\title{
Mescitli (Torul/Gümüşhane) ve Çevresindeki Eosen Yaşlı Volkanik Kayaçların Petrografik, Jeokimyasal ve Petrolojik Özellikleri
}

\author{
Kübra ŞAHİN ${ }^{1}$, Abdullah KAYGUSUZ ${ }^{2 *}$ \\ ${ }^{1}$ Demir Export Anonim Şirketi, Gümüşhane \\ ${ }^{2}$ Gümüşhane Üniversitesi, Jeoloji Mühendisliği Bölümü, Gümüşhane
}

Geliş tarihi/Received 10.02 .2016

Düzeltilerek geliş tarihi/Received in revised form 08.04.2016

Kabul tarihi/Accepted 20.04.2016

$\ddot{O} z$

Doğu Pontid'lerin Güney Zonunda Mescitli (Torul/Gümüşhane) ve çevresinde yüzeylenen Eosen yaşlı volkanik kayaçlar mineralojik, petrografik ve jeokimyasal olarak incelenmişstir. Mescitti volkanitleri bazaltik andezit, bazaltik traki andezit, traki andezit, andezit, dasit ve riyolit bileşiminde olup, başlica plajiyoklas, alkali feldispat, kuvars, hornblend, ojit ve biyotit minerallerinden oluşurlar. Volkanitler kalk-alkali karakterli olup, orta-yüksek $K$ içeriğine sahiptirler. Büyük iyon yarıçaplı litofil elementler ve hafif nadir toprak elementlerce zenginleşmiş, yüksek çekim alanlı elementler bakımından tüketilmişlerdir. Kondrite normalize edilmis nadir toprak element dăğllimları, düşük-orta derecede zenginleşmeyle konkav şekilli olup ( $L a_{N} / L u_{N}=5$ 14), volkanitleri oluşturan kayaçların benzer kaynaktan itibaren oluştukların gösterirler. Volkanitlerin geliş̧iminde başlıca ayrımlaş̧ma, daha az oranda da özümleme \pm magma karışımı rol oynamıştır. Tüm bu veriler, volkanitlerin köken magmasinın muhtemelen daha önce yitimle ilişkili olaylardan türeyen slviların metazomatizması yoluyla zenginleşmiş, yarı kıtasal litosferik manto kaynağı olabileceğini gösterir.

Anahtar kelimeler: Doğu Pontidler, Eosen, Jeokimya, Mescitli volkanitleri, Petroloji, Torul

\section{Petrographical, geochemical and petrological features of Eocene volcanic rocks in the Mescitli (Torul/Gümüşhane) and surrounding area}

\begin{abstract}
Eocene volcanic rocks of the Mescitli (Torul/Gümüşhane) and surrounding area in the southern part of the Eastern Pontides are investigated as mineralogical, petrographical and geochemical. Mescitli volcanic rocks are basaltic andesite, basaltic trachy andesite, trachy andesite, andesite, dacite and rhyolite in composition, and consists of mainly plagioclase, alkali feldspar, quartz, hornblende, augite and biotite minerals. They show calc-alkaline affinities and have medium to high $K$ contents. They are enriched in large ion lithophile and light rare earth elements, with pronounced depleted of high field strength elements. The chondrite-normalized REE patterns $\left(L a_{N} / L u_{N}=5-14\right)$ show low to medium enrichment, indicating similar sources for the rock suite. The main solidification processes involved in the evolution of the volcanics consist of fractional crystallization with minor amounts of crustal contamination \pm magma mixing. All evidence supports the conclusion that the parental magma of the rocks probably derived from an enriched subcontinental lithospheric mantle, previously metasomatized by fluids.
\end{abstract}

Keywords: Eastern Pontides, Eocene, Geochemistry, Mescitli volcanic rocks, Petrology, Torul

\footnotetext{
*Abdullah KAYGUSUZ, abdullah.kaygusuz@ gmail.com, Tel: (0456) 23310 00-1707
} 


\section{Giriş}

Alpin-Himalaya orojenik kuşağında yer alan Doğu Pontidler (KD Türkiye), volkanik ve plütonik kayaçların yaygın olarak gözlendiği önemli alanlardan biridir. Doğu Pontid'lerde, Liyas, Kretase ve Eosen (ve sonrasinda) olmak üzere üç ana volkanik devre belirlenmiştir (Adamia vd., 1977; Şengör ve Yllmaz, 1981; Kazmin vd., 1986; Korkmaz vd., 1995; Çamur vd., 1996; Arslan vd., 1997). Doğu Pontid'ler, Kretase yaşlı kayaçların litolojik olarak kuzey ve güney bölgelerde farklılık göstermesinden dolayı Özsayar vd., (1981) tarafindan Kuzey ve Güney Zon olarak ikiye ayrılmıştır. Buna göre inceleme alanı Doğu Pontid Güney Zonu'nda yer almaktadır.

Doğu Pontidler'de Tersiyer volkanitlerin gelişimi ile ilgili yapılan çalışmalarda; Tokel (1972; 1977), Eosen volkanitlerinin kalkalkali özellikte ada yayı volkanizması ürünleri olduğunu belirtmiştir. Çamur vd., (1996), bölgedeki volkanitlerin yitim esnasında oluşum evrimine giren hareketli elementler bakımından zengin akışkanlarca ikincil bir zenginleşmeye uğrayan OOSB benzeri bir mantodan türediklerine işaret etmişlerdir. Arslan vd., (1997), yöredeki volkanik kayaçların ana magmasının alt kabuk ve/veya üst mantodan türediğini belirtmiştir. Arslan ve Aliyazıcıoğlu (2001), Eosen yaşlı volkanitlerin tabanında yer alan mikritik kireçtaşlarında ve aglomeralar içindeki mikritik kireçtaşlarında bulunan Paleosen fosillerine dayanarak, Eosen volkanizmasının Paleosen döneminde başladığını ve ekstansiyonel rejimdeki havzada geliştiğini belirtmişlerdir. Şen vd., (1998), Doğu Pontid Alkalen Volkanik Provensi'nde, Eosen yaşlı Trabzon ve Tonya grubu volkanitlerinin, metasomatizmaya uğramış bir manto kaynağından türeyen ve sı ̆ derinlikte diferansiyasyona uğrayan birincil bir magma ile ilişkili olabileceğini belirtmişlerdir. Arslan vd. (2000), Trabzon ve Gümüşhane yörelerinde yüzeylenen Eosen volkanitlerinde magma karışımı ve kirlenme olaylarının belirleyici rol oynadığını belirtmişlerdir. Barbieri vd., (2000), Kuzey Zon'daki
Senozoyik yaşlı volkanitlerin yaşlarının 26 My etrafinda kümelendiğini, Trabzon güneyinden alınan silise doymamış alkali örneğin 26.5-27 My yaşında olmasını, yöredeki Senozoyik volkanitlerinin en son ürünü olarak yorumlamışlardır. Şen (2000), Doğu Karadeniz Bölgesi'nin kuzeyindeki Eosen sonrası kayaçlar içerisinde "ultramafik nodüllerin" varlığını ortaya koymuş ve bu nodüllerin manto kalıntısı olmadığını, magmanın değişik derinliklerinde kristallenen mineral birikimleri olduğunu belirtmiştir. Kaygusuz (2000), Torul yöresindeki Eosen volkanitlerinin kalk-alkalen karakterde olduğunu belirtmiştir. Aydın vd., (2008), Trabzon yöresinde yer alan Neojen yaşlı alkalen volkanik kayaçların K-Ar yaşlarının 5.1 ile 3.2 My arasında olduğunu vurgulamışlardır. Aslan (2010), Gümüşhane civarındaki Eosen yaşlı kayaçlara ait tüflerin $\mathrm{U}-\mathrm{Pb}$ zirkon yaşının 45.8 My olduğunu ve volkanitlerin ana magmasının zenginleşmiş üst manto kaynağından türediğini belirtmiştir. Kaygusuz vd., (2011a), Eosen yaşlı Torul volkanitlerinin $\mathrm{K} / \mathrm{Ar}$ yaşlarının 33.45 ila 43.99 My aralığında (Orta-Üst Eosen) olduğunu, volkanitlerin ${ }^{87} \mathrm{Sr}^{86} \mathrm{Sr}_{(\mathrm{i})}$ değerlerinin 0.70457-0.70511 arasında, ${ }^{143} \mathrm{Nd} /{ }^{144} \mathrm{Nd}_{(\mathrm{i})}$ değerlerinin ise 0.51264 ila 0.51278 arasında olduğunu ve köken magma(lar)sının muhtemelen daha önceki yitim akışkanları tarafından metasomatizmaya uğratılmış zenginleşmiş bir üst manto kaynağından oluştuğunu ifade etmişlerdir. Eyüboğlu vd., (2011a, b), Doğu Pontidler'deki Tersiyer magmatizmasının 57 milyon yıl önce (Geç Paleosen) Kop Dağ1Erzincan hattı boyunca adakitik karakterli olarak başladığını, zaman içinde kuzeye doğru göç ettiğini ve 45 milyon yıl önce TorulBayburt-İspir hattı boyunca adakitik magmatizmanın son ürünlerini oluşturduğunu belirtmişlerdir. Temizel (2008), Doğu Pontidler'de Ulubey (Ordu) yöresindeki Tersiyer volkaniklerinin ${ }^{40} \mathrm{Ar}-{ }^{39} \mathrm{Ar}$ yaşlarının 15.1 ile 49.1 My arasında olduklarını ortaya koymuştur. Aydınçakır (2012), Borçka (Artvin) civarındaki volkanik kayaç örneklerinin ${ }^{40} \mathrm{Ar}^{39}{ }^{39} \mathrm{Ar}$ yaşlarının 39.9 ile 46.0 My arasında değiştiğini belirtmiştir. Temizel vd., (2012), Ulubey (Ordu) yöresindeki 
Tersiyer yaşlı volkanik kayaçların köken magmasının daha önceden akışkanlar ve sedimanlar tarafindan metasomatizmaya uğratılmış yitim ve astenosferik ergiyiklerin karışımından oluşan zenginleşmiş bir kaynak bölgeden türediğini ortaya koymuşlardır. Yücel (2013), Trabzon-Giresun arasındaki Tersiyer yaşlı volkanik kayaçların ${ }^{40} \mathrm{Ar}-{ }^{39} \mathrm{Ar}$ yaşlarının 5.8 ile 44.7 My arasında olduğunu, çarpışma sonrası ekstansiyonel jeodinamik evrimine sahip olduğunu ve yitim akışkan \pm ergiyikleri ile zenginleşmiş litosferik mantodan türeyen ana magmalardan karmaşık magmatik süreçlerle farklılaştıklarını vurgulamıştır. Aslan vd., (2014), Gümüşhane yöresindeki andezitik lavların K-Ar yaşlarının 30.02 ile 37.62 My arasinda, bazaltik daykların K-Ar yaşının ise $15.80 \mathrm{My}$ olduğunu belirtmişlerdir.

Bu makalede Mescitli (Torul/Gümüşhane) ve civarındaki Eosen yaşlı volkanik kayaçların petrografik, jeokimyasal ve petrolojik özellikleri ortaya konularak, Doğu Pontid Tersiyer magmatizmasının gelişimine açıklık getirilmeye çalışılacaktır.

\section{Genel Jeoloji}

Doğu Pontid Orojenik Kuşağı'nın en yaşlı kayaçları Güney Zon'da Pulur masifi (Topuz ve Altherr, 2004; Topuz vd., 2004a, b, 2007), Ağvanis masifi (Okay, 1984; Altunkaynak, 2000), Tokat metamorfik masifi (Alp, 1972; Özcan vd., 1980; Rojay, 1993; Tüysüz 1996; Y1lmaz vd., 1997; Eyüboğlu, 2006), Kurtoğlu metamorfitleri (Topuz vd., 2007, 2010), Karadağ metamorfitleri (Dokuz, 2000; Dokuz ve Tanyolu, 2006; Ustaömer ve Robertson, 2010), Kopuzsuyu metamorfik kayaçları, Gümüşhane Batoliti (Tokel, 1972; Çoğulu, 1975; Y1lmaz, 1976; Özdoğan, 1992; Topuz vd., 2010) ve Köse Batoliti (Dokuz, 2011) ile temsil edilirken; magmatik yayın kuzeyinde küçük mostralar halinde Tonya güneyinde Derinoba ve Kayadibi granitleri (Kaygusuz vd., 2012a, b, 2013), Özdil yöresinde Özdil Granitoyidi (Kaygusuz vd., 2013, 2016) ve Maçka yöresinde Soğuksu ve Seslikaya granitleri (Kaygusuz vd., 2013, 2016) ile temsil edilirler. Bununla birlikte metamorfizma yaşları tam olarak bilinmemekle birlikte Kuzey Zon'da Dereli (Giresun) ve Çaykara (Trabzon) yörelerinde gözlenen metamorfik kayaçlarında bölgenin taban kayaçlarını temsil ettiği görüşü yaygındır (Schultze-Westrum, 1961; Zankl, 1962; Boynukalın, 1990).

Doğu Pontid Orojenik Kuşağı'nda Triyas dönemini temsil eden kayaçların varlığ tartışmalıdır. Bayburt Demirözü yöresinde metamorfik kayaçlar üzerine gelen ve kırıntılı kayaçlardan oluşan istifin (Ăgar, 1977; Yılmaz vd., 1997; Topuz vd., 2004) ve Amasya yöresinde Tokat masifini oluşturan metamorfik kayaçlar üzerine gelen ve çok düşük dereceli metamorfizma izleri taşıyan kırıntılı kayaçlardan oluşan birimin (Alp, 1972) Triyas yaşlı olduğu belirtilmiştir. Eyüboğlu vd., (2010, 2011a, b), Pulur ve Tokat metamorfik masiflerini kesen ultramafik ve mafik intrüzyonların Geç Triyas yaşlı (191 ile 212 My) olduklarını belirtmişlerdir. Doğu Pontid Orojenik Kuşağı'nda Paleozoyik ve Triyas yaşlı kayaçlar Erken-Orta Jura yaşlı volkano-tortul istif tarafindan uyumsuz olarak örtülür. Kuşağın Kuzey Zonu'nda Jura yaşlı sedimanter oluşuklara seyrek rastlanılmakta (Giresun, Dereli) olup, birim genellikle volkanik kayaçlar ile temsil edilmektedir (Boynukalın, 1990; Eyüboğlu, 2006; Şen 2007; Kaygusuz vd., 2012, 2013). Doğu Pontid Orojenik Kuşağı'nın Güney Zonu'nda, Kuzey Zon'dan farklı olarak Erken-Orta Jura dönemi sedimanter ağırlıklı bir istif ile temsil edilir ve daha geniş alanlarda yüzeyleme verir (Saydam Eker vd., 2012). Geç Jura-Erken Kretase dönemi Doğu Pontid Orojenik Kuşağı'nın tamamında tektonik ve magmatik açıdan duraylılık dönemine karşılık gelmekte olup, tüm bölgede karbonat çökelimi egemendir. İlk kez Pelin (1977) tarafindan Berdiga Formasyonu olarak isimlendirilmiş olan birim, Kuzey Zon'da genellikle masif tabakalanmal, gri-bej renkli, yanal devamlılığı olmayan kireçtaşları ile temsil edilir (Tasl1, 1984). Magmatik yayın güney kesiminde ise bu birim genel olarak gri-bej renkli, kalın, yer yer masif katmanll, çok zengin bentik foraminifer fosilleri içeren, taban seviyeleri yer yer dolomitlerden üst seviyeleri ise çört yumru ve bantlı 
kireçtaşlarından oluşan, sı ̆ denizel bir istif özelliği sunar (Taslı, 1990; Kırmac1, 1992; Yılmaz, 2002). Geç Kretase dönemi, Doğu Pontid Orojenik Kuşağı'nda kuzeyden güneye doğru önemli litolojik farklılıklar gösterir. Kuzey Zon'da şiddetli bir magmatizmanın ürünü olan volkanik kayaçlar ve granitoyidik intrüzyonlar baskın litolojiyi oluşturur (Bektaş, 1984; Jica, 1986; Gedik vd., 1992; Y1lmaz ve Boztuğ, 1996; Okay ve Şahintürk, 1997; Güngör vd., 1997; Köprübaş1 vd., 2000; Kaygusuz, 2000; Boztuğ vd., 2004, 2006; Şahin vd., 2004; Karsl1 vd., 2004, 2010; Sipahi, 2005, 2011; Kaygusuz vd., 2008, 2009，2010，2011a，2012a， b，2013，2014; Kaygusuz ve Aydınçakır, 2009, 2011; Kaygusuz ve Şen, 2011, Sipahi ve Sadiklar, 2014; Sipahi vd., 2014; Aydınçakır ve Şen, 2013). Magmatizmanın durakladığı dönemlerde ise tortul ara seviyelerin çökelimi söz konusudur. Güneye doğru ilerledikçe magmatizmanın şiddeti azalır ve magmatik kayaç ağırlıklı istif yerini sedimanter kayaç ağırlıklı bir istife bırakır. Daha güneyde Bayburt-Amasya hattı boyunca ise magmatizma yaygın olarak gözlenir (Altherr vd., 2008; Topuz vd., 2010; Eyüboğlu, 2010).

Senozoyik dönemi Doğu Pontid Orojenik Kuşağı'nın güney kesiminde sedimanter, kuzey kesiminde ise magmatik ağırlıklı bir istif ile temsil edilmektedir. Güneyde Senozoyik magmatizması Kop Dağları ve Erzincan hattı üzerinde Geç Paleosende başlamış ve kuzeye doğru ilerleyerek Erken Eosen döneminde Gümüşhane-İspir hattı boyunca asidik magmatizma ve volkanosedimanter istif özelliğindeki ürünleri oluşturmuştur (Tokel, 1977; Arslan ve Aliyazıcıoğlu, 2001; Topuz vd., 2005; Arslan ve Aslan, 2006; Temizel ve Arslan, 2009; Aslan, 2010; Karslı vd., 2007, 2010, 2011; Kaygusuz vd., 2011a; Topuz vd., 2011; Eyüboğlu vd., 2011; Çakmak, 2013; Çakmak ve Kaygusuz, 2014; Öztürk, 2014; Kaygusuz ve Öztürk, 2015). Doğu Pontid'lerin Kuzey Zon'unda Senozoyik döneminde magmatizma Güney Zon'dakine göre daha şiddetlidir ve bu dönemde kalk-alkalin granitoyidik ve bazik volkanik kayaçların oluşumu söz konusudur (Yılmaz ve Boztuğ, 1996; Şen vd., 1998; Boztuğ vd., 2004; Karslı vd., 2011) (Şekil 1).
Sahil kesiminde ise Neojen yaşlı alkalen volkanizma bölgedeki magmatik faaliyetlerin son ürünlerini oluşturur (Aydın, 2003; Aydın vd., 2008; Yücel, 2013; Yücel vd., 2014). Güneyde Neojen tortulları jipsli, tuzlu sı ̆ deniz, lagün ve gölsel fasiyesler olarak gözlenmiştir (Erentöz, 1974; Ketin, 1983). Kuvaterner yaşlı oluşuklar traverten ve alüvyonlardan oluşurlar.

Doğu Pontid Tektonik Birliği Güney Zonu'nda yer alan ve genelde volkanik ve tortul kayaçların egemen olduğu çalışma alanında, en yaşlı kayaçları Liyas yaşlı Hamurkesen Formasyonu oluşturur (Şekil 2). Birim Dogger-Malm-Alt Kretase yaşlı Berdiga Formasyonu tarafindan uyumsuz olarak üstlenir. Geç Kretase yaşlı Mescitli Formasyonu bu birim üzerine uyumsuz olarak gelir. Tüm bu birimler Eosen yaşlı Alibaba Formasyonu tarafından uyumsuz olarak üstlenir. İnceleme alanının en genç birimini Kuvaterner yaşlı alüvyonlar oluşturur (Şekil 2).

$\mathrm{Bu}$ çalışmanın ana konusunu oluşturan Alibaba Formasyonu inceleme alanında en fazla yüzeylemeye sahip olup, başlıca Son Mahallesi, Beyaztaşlı Tepe, Bozbentçatağı Tepe, Kilavuz Tepe, Güney Tepe, Kabak Tepe, Dilim Kayaları, Bozbent Dağı ve Hırsız Dağı civarında yüzeylenir (Şekil 2). Bu birim tabanda volkanik breş, aglomera ve tüfler ile başlamakta, bunu killi kireçtaşı ve kumtaşı ara seviyeli hornblend/ojit andezit, kuvarsl andezit ve tüflerden oluşan birimler üstlemekte, en üstte ise riyolit, dasit ve piroklastitlerinden oluşan birimler yer almaktadır. Aglomera ve breşler makroskobik olarak koyu gri, yeşil renkte olup, andezit çakılları bir matriks ile bağlanmışlardır. Andezit çakıllarının boyutları 5-25 cm arasında değişmekte olup, aglomeralarda yuvarlak veya oval, breşlerde ise köșeli şekildedirler. Tortul kayaçlar, inceleme alanında en belirgin şekilde Kabak Tepe civarında görülmekte olup, killi kireçtaşı, kumlu kireçtaşı ve kumtaşı merceklerinden oluşur. Andezitler gri, koyu gri ve yeşilimsi gri renkte olup, yer yer kalsit ve kuvars damarları içerirler. 


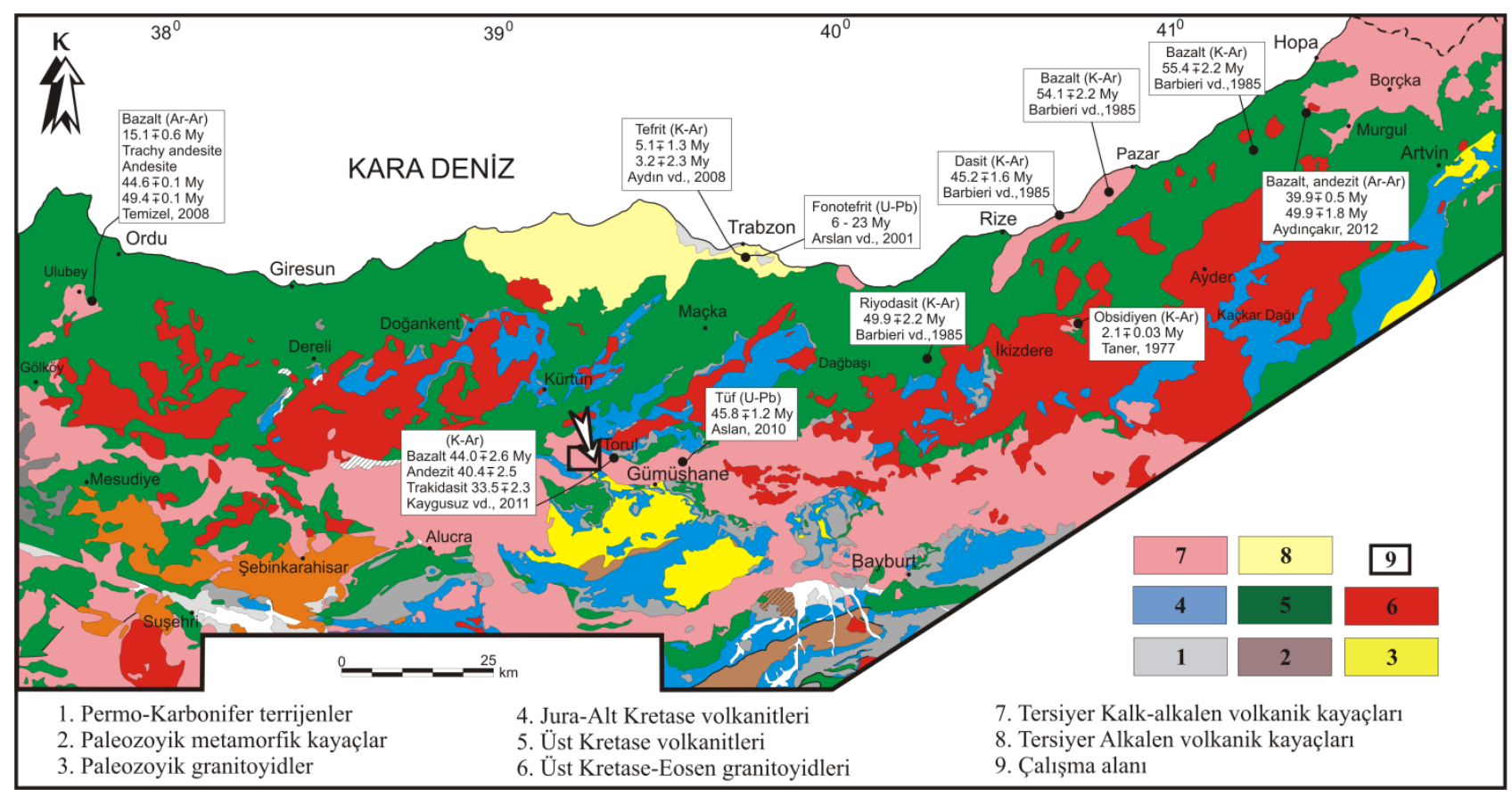

Şekil 1. Doğu Pontidler'deki Tersiyer volkanitleri ve bunları kesen sokulumların yayılımları ile Tersiyer yaşlı volkanitlerden elde edilen jeokronolojik yaşlar (Güven, 1993 ve Aydınçakır, 2012'den değiştirilerek).

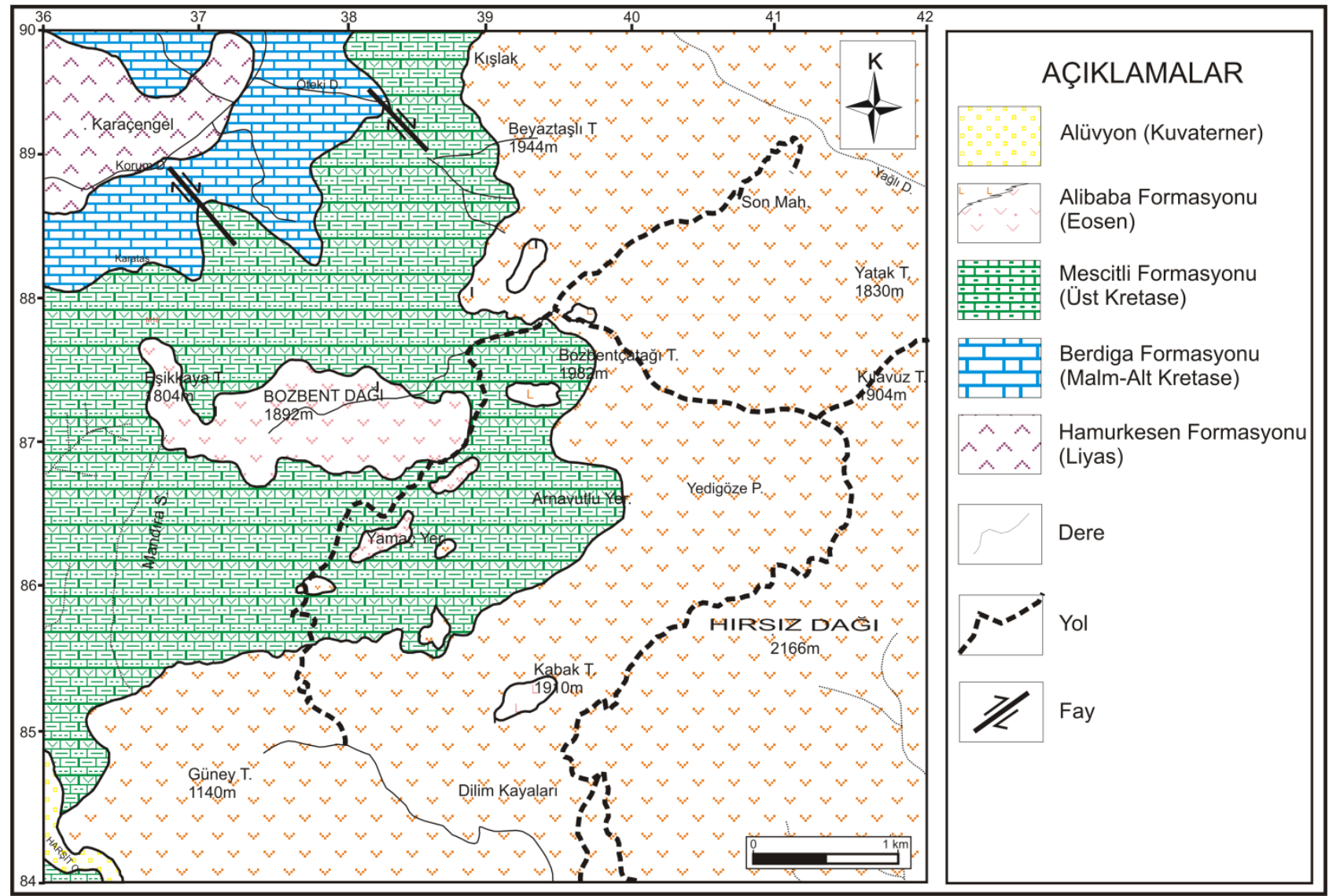

Şekil 2. İnceleme alanının jeoloji haritası (Şahin, 2014'den değiştirilerek). 
Dasit ve riyolitler inceleme alanında Bozbentdağı Tepe ve Kabak Tepe civarında küçük kütleler halinde görülürler. Renkleri açı gri, pembemsi gri ve gridir. Alibaba Formasyonu'na ait andezit ve piroklastitleri bazalt bileşimli dayklar tarafından kesilmiştir. Bazalt daykları, inceleme alanında Hirsız Dağı civarında aglomeraları kesmiş olup, koyu gri ve siyah renktedir.

\section{Analiz Yöntemleri}

Çalışma kapsamında, araziden derlenen kayaç örneklerinin ince kesitleri hazırlanmış ve polarizan mikroskopta ayrıntılı petrografik özellikleri belirlenmiştir. İnceleme alanına ait 16 adet kayaç örneğin ana, iz ve nadir toprak element analizleri Kanada'da Vancouver, BC Analiz (ACME) Laboratuvarı'nda yapılmıştır. Ana ve iz elementler ICP (Inductively Coupled Plasma) yöntemiyle, nadir toprak elementler (NTE) ise ICP-MS (Inductively Coupled Plasma-Mass Spectrometry) yöntemiyle ile analiz edilmiştir. Ana ve iz element analizleri için $0.2 \mathrm{gr}$ toz örnek $1.5 \mathrm{gr}$ $\mathrm{LiBO}_{2}$ ile karıştırılarak, \% $5 \mathrm{HNO}_{3}$ içeren bir sıv1 içinde çözündürülmesinden itibaren analiz edilirken, nadir toprak element analizleri için 0.250 gr toz örnek dört farklı asit içinde çözündürülmüş ve analiz edilmiştir. Ateşte kayıp (LOI), örnekler 1000 ${ }^{\circ} \mathrm{C}$ 'de yakıldıktan sonra ağırlık farkından hesaplanmıştır. Toplam $\mathrm{Fe}$ içeriğgi, $\mathrm{Fe}_{2} \mathrm{O}_{3}$ cinsinden ifade edilmiştir. Dedeksiyon limitleri, ana oksitler için \% ağırlık olarak 0.002 ilâ 0.04 , iz elementler için 0.1 ilâ 8 ppm ve NTE için 0.01 ilâ 0.3 ppm arasındadır.

\section{Mineraloji ve Petrografi}

Çalışmanın ana konusunu oluşturan Eosen yaşlı Mescitli volkanitlerine ait andezit, dasit ve riyolit türü kayaçların dokusal özellikleri ile mineralojik-petrografik bileşimleri incelenmiştir. Andezitlerin mikroskobik incelemesinde porfirik, kısmende mikrolitik porfirik ve trakitik doku görülür. Plajiyoklas iri öz ve yarı öz şekilli uzun kristaller, hamurda da küçük kristaller halinde bulunur. İri kristaller genellikle zonlu yap1 gösterir. Albit ikizi sunanlarda yapılan cins tayininde (010’a dik kesit) An içeriğinin 32-38 arasında değiştiği ve andezin olduğu belirlenmiştir. Bazı minerallerde albit ikizi, bazılarında da polisentetik ikiz görülür. En yaygın ayrışma ürünleri kalsit, klorit ve kil mineralleridir. Hornblendler iri öz ve yarı öz şekilli prizmatik kristaller, hamurda da küçük kristaller halinde görülür. Bazı mineraller plajiyoklas ve opak mineral inklüzyonları içerirler. (010) yüzeyine paralel kesitlerde yaklaşık 24-25 derece arasında sönme açıları gösterirler. Genelde kalsite ayrışmış ve kenar kısımlarda opak mineraller gelişmiştir. Ojitler genelde iri prizmatik kristaller, hamurda ise küçük taneler halinde bazı kesitlerde görülür. (010) yüzeyine paralel kesitlerde sönme açıları yaklaşık 40-43 derece arasında değişir. Biyotitler genellikle küçük prizmatik kristaller halindedir ve bazı kesitlerde görülür. Kırmızımsı kahverengi ve sarımsı kahverengi pleokroizma belirgindir. Opak mineraller az miktarda küçük taneler halinde ve dağınık olarak bulunur. İkincil mineraller kalsit, klorit, serizit ve epidot minerallerinden oluşur. Hamur plajiyoklas, ojit, hornblend ve biyotit minerallerinin mikro ve kripto kristallerinden ve opak mineral tanelerinden oluşur (Şekil 3).

Dasit/riyolitlerin mikroskobik olarak mikrogrönü porfirik dokuda oldukları gözlenmiştir. Plajiyoklaslar iri, öz şekilli levhamsı kristaller, hamurda da mikrolitler halinde bulunur. İri plajiyoklas kristalleri küçük hornblend ve opak mineral inklüzyonları içerir. Plajiyoklaslar bolluk sırasına göre albit ve albit-karlsbad ikizleri gösterirler. 010'a dik kesitlerde yapılan cins tayininde cinsinin \% 36-42 An içerikli andezin olduğu saptanmıştır. Bazı örneklerde zonlanma görülmektedir. En yaygın ayrışma türü serizitleşme, kalsitleşme ve killeşme şeklindedir. Alkali Feldispatlar iri, öz veya yarı öz şekilli kristaller halinde olup hamurda küçük kristaller halinde bulunur. Bazı minerallerde karlsbad ikizlenmesi gözlenir. Kuvars genelde iri ve özsekilli kristaller halindedir. İri kristallerin bazılarının kenarları hamur tarafından yenmiştir (Şekil 3d). İri kristaller genelde dalgalı sönme gösterirler ve kırıklı yapıdadır. Biyotitler öz ve yarı özşekilli çubuğumsu prizmatik kristaller ve lameller halindedir. İncelenen kayaçlarda en 
bol bulunan koyu renkli mineraldir. Bazı kesitlerde kenarlardan itibaren k1smen ayrışarak klorite dönüşmüş olarak gözlenmektedir. Ayrışma sonucu açığa çıkan demir, dilinimler boyunca opak oksit yı ğışımlarına neden olmuştur. Hornblendler öz ve yarı özşekilli levhamsı prizmatik kristaller halindedir. (010) yüzeyine paralel kesitlerde maksimum sönme açıları 14-16 derece arasındadır. Bazı kesitlerde ayrışarak klorit ve kalsite dönüşmüş olarak görülür. Opak mineraller öz ve yarı özşekilli hem iri hem küçük kristaller halinde bulunur. Hamur plajiyoklas, kuvars, biyotit, hornblend ve opak minerallerin mikro ve kriptokristallerinden oluşur. Tali mineraller zirkon ve apatit minerallerinden oluşurlar. Ayrışma minerallerini klorit, serizit ve kalsit oluşturur (Şekil 3).
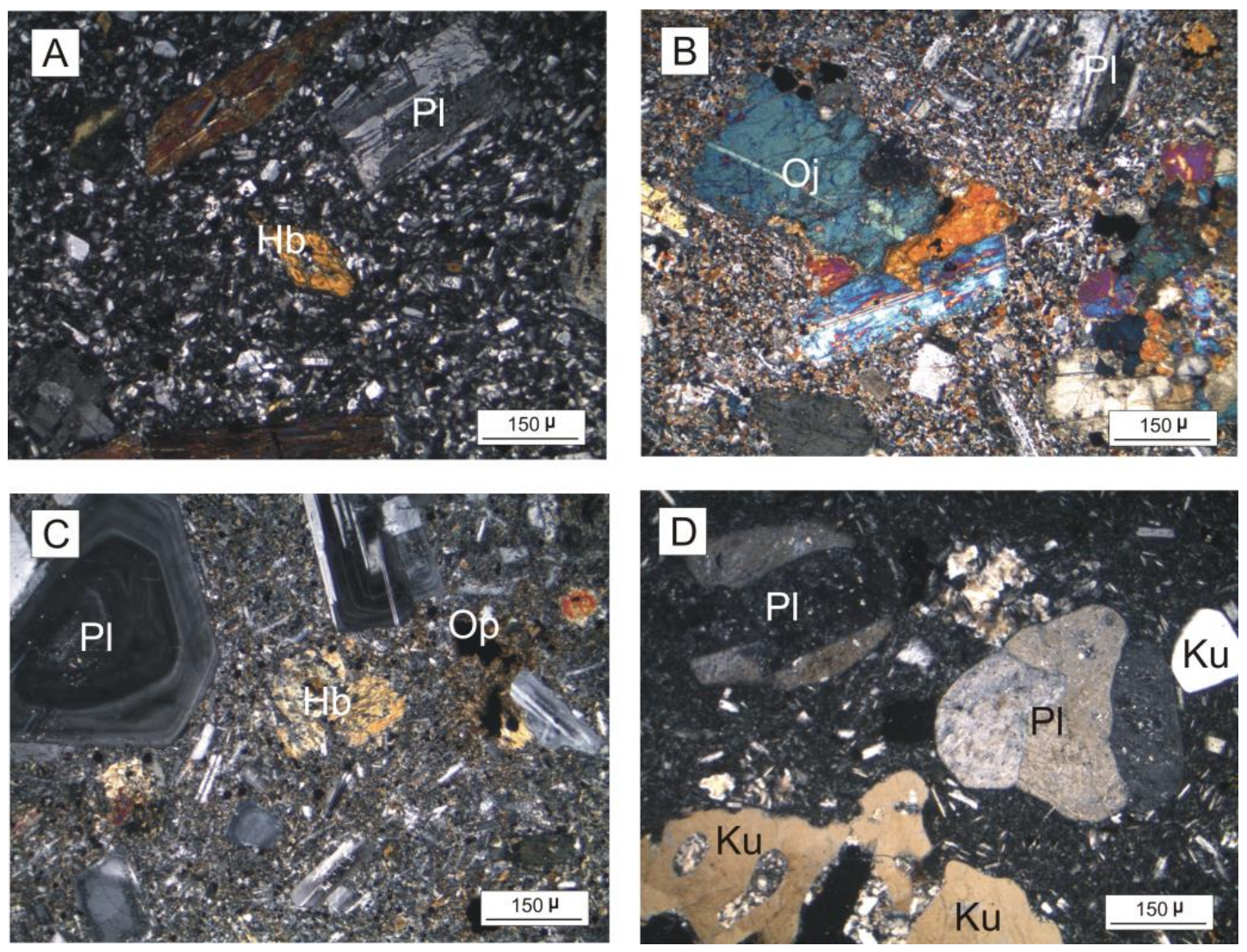

Şekil 3. Mescitli volkanitlerine ait, a) Andezitlerdeki mikrolitik porfirik doku, b) Andezitlerdeki iri ojit minerali, c) Andezitlerdeki zonlu plajiyoklas minerali, d) Dasitlerde gözlenen mikrogrönü porfirik doku ve hamur tarafindan yenmiş iri kuvars mineralleri (Ç.N., Pl: Plajiyoklas, Ku: Kuvars, Oj: Ojit, Hb: Hornblend, Op: Opak mineral)

\section{Eosen yaşlı Mescitli volkanitlerinin jeokimyasal özellikleri}

\subsection{Ana ve iz elementler}

Mescitli volkanitlerine ait 16 adet örneğin ana, iz ve nadir toprak element analizleri de Tablo 1'de verilmiştir.

İncelenen örneklerin $\mathrm{SiO}_{2}$ değerleri \% 52.4673.48 arasında olup, bazaltik andezitlerde en düşük (52.46-55.40), riyolitlerde ise en yüksektir (69.95-73.48). Örneklerin $\mathrm{K}_{2} \mathrm{O} / \mathrm{Na}_{2} \mathrm{O}$ oranları $0.37-1.40$ arasinda olup, andezitlerde en düşük (0.37-0.97), traki andezitlerde en yüksektir (1.04-1.19). Örneklerin Magnezyum numaraları $\left[\mathrm{Mg} \#=100 *\left(\mathrm{MgO} / \mathrm{MgO}+\mathrm{Fe}_{2} \mathrm{O}_{3}{ }^{\mathrm{T}}\right)\right]$ ise 9.3338.74 arasında olup, riyolitlerde en düşük (9.33-20.73), bazaltik andezitlerde en yüksektir (26.58-38.59) (Tablo 1). 
Tablo 1. Mescitli volkanitlerine ait kayaçların ana (\%), iz (ppm) ve nadir toprak element (ppm) analizleri

\begin{tabular}{|c|c|c|c|c|c|c|c|c|c|c|c|c|c|c|c|c|}
\hline \multirow{2}{*}{$\begin{array}{l}\text { Kayaç } \\
\text { Adi } \\
\text { Örnek } \\
\end{array}$} & \multicolumn{2}{|c|}{$\begin{array}{l}\text { Bazaltik } \\
\text { andezit }\end{array}$} & \multicolumn{2}{|c|}{\begin{tabular}{|l} 
Bazaltik \\
traki-andezit
\end{tabular}} & \multicolumn{2}{|c|}{ Andezit } & \multicolumn{2}{|c|}{ Traki-andezit } & \multicolumn{2}{|l|}{ Dasit } & \multicolumn{6}{|c|}{ Riyolit } \\
\hline & B11 & B46 & B58 & B41 & 012 & B33 & M19 & M4 & B24 & B4 & M27 & M17 & M1 & B8 & M26 & M13 \\
\hline$\overline{\mathrm{SiO}_{2}}$ & 52.46 & 55.4 & 53.35 & 53.6 & 59.19 & 59.25 & 57.71 & 60.95 & 63.39 & 63.76 & 69.95 & 70.99 & 71.02 & 71.8 & $\begin{array}{l}73.37 \\
\end{array}$ & 73.48 \\
\hline $\mathrm{TiO}_{2}$ & 0.56 & 0.58 & 0.63 & 0.63 & 0.57 & 0.61 & 0.57 & 0.42 & 0.4 & 0.39 & 0.3 & 0.64 & 0.48 & 0.54 & 0.24 & 0.4 \\
\hline $\mathrm{Al}_{2} \mathrm{O}_{3}$ & 16.16 & 16.17 & 16.06 & 17.7 & 15.87 & 15.21 & 14.54 & 18.25 & 16 & 14.79 & 15.06 & 14.77 & 14.26 & 15.06 & 12.57 & 13.03 \\
\hline $\mathrm{Fe}_{2} \mathrm{O}_{3}{ }^{\mathrm{T}}$ & 7.43 & 7.16 & 8.22 & 7.99 & 6.35 & 6.04 & 6.62 & 3.4 & 4.41 & 4.76 & 1.95 & 3.11 & 2.2 & 1.54 & 1.97 & 2.09 \\
\hline $\mathrm{MnO}$ & 0.12 & 0.13 & 0.14 & 0.16 & 0.1 & 0.11 & 0.09 & 0.11 & 0.08 & 0.07 & 0.14 & 0.06 & 0.04 & 0.02 & 0.05 & 0.07 \\
\hline $\mathrm{MgO}$ & 2.69 & 4.5 & 4.7 & 3.95 & 2.28 & 2.61 & 2.65 & 2.15 & 2.36 & 1.74 & 0.51 & 0.32 & 0.51 & 0.17 & 0.5 & 0.47 \\
\hline $\mathrm{CaO}$ & 9.83 & 6.13 & 6.11 & 6.82 & 5.28 & 6.16 & 6.71 & 3.58 & 4.08 & 3.64 & 2.37 & 1.12 & 1.76 & 2.53 & 0.99 & 1.6 \\
\hline $\mathrm{Na}_{2} \mathrm{O}$ & 2.08 & 2.49 & 3.28 & 3.96 & 3.48 & 2.95 & 3.06 & 3.57 & 4.37 & 3.29 & 3.02 & 4.34 & 4.18 & 3.92 & 3.44 & 3.81 \\
\hline $\mathrm{K}_{2} \mathrm{O}$ & 1.49 & 2.14 & 2.36 & 1.47 & 2.54 & 2.85 & 3.64 & 3.73 & 1.88 & 3.58 & 3.87 & 2.52 & 3.09 & 2.7 & 2.5 & 3.07 \\
\hline $\mathrm{P}_{2} \mathrm{O}_{5}$ & 0.09 & 0.16 & 0.24 & 0.18 & 0.23 & 0.2 & 0.12 & 0.1 & 0.14 & 0.09 & 0.08 & 0.12 & 0.08 & 0.1 & 0.06 & 0.07 \\
\hline LOI & 6.9 & 4.9 & 4.1 & 3.3 & 3.4 & 3.7 & 3.7 & 2.9 & 2.6 & 3.5 & 2.5 & 1.9 & 2.2 & 1.1 & 3.6 & 1.8 \\
\hline Toplam & 99.81 & 99.76 & 99.19 & 99.76 & 99.29 & 99.69 & 99.41 & 99.16 & 99.71 & 99.61 & 99.75 & 99.89 & 99.82 & 99.48 & 99.29 & 99.89 \\
\hline$\overline{\mathrm{Ga}}$ & 14.5 & 16.2 & 15 & 17.6 & 16.1 & 13.4 & 11.9 & 8.5 & 15.9 & 14.3 & 12.9 & 10.7 & 12 & 12.1 & 8.9 & 9.6 \\
\hline $\mathrm{Ni}$ & 13.5 & 8.2 & 8.6 & 6.8 & 3.5 & 8.1 & 8.3 & 3.8 & 13.6 & 3 & 1.4 & 2.1 & 1.2 & 1 & 1.1 & 0.8 \\
\hline V & 182 & 212 & 226 & 206 & 213 & 171 & 157 & 76 & 106 & 85 & 34 & 20 & 15 & 9 & 18 & 12 \\
\hline $\mathrm{Cu}$ & 68.8 & 14 & 87.9 & 86.2 & 23.2 & 208.1 & 16.2 & 12.4 & 44.1 & 23.2 & 7.1 & 2.9 & 1.7 & 2.1 & 2.8 & 1.4 \\
\hline $\mathrm{Pb}$ & 12.5 & 3.7 & 5.5 & 8.1 & 12.7 & 7.1 & 5.7 & 15.6 & 14.3 & 17.6 & 27.4 & 16.3 & 21.5 & 14 & 26.1 & 18.7 \\
\hline $\mathrm{Zn}$ & 53 & 52 & 37 & 58 & 40 & 34 & 53 & 79 & 64 & 48 & 51 & 90 & 44 & 7 & 29 & 30 \\
\hline W & 1.5 & 0.7 & 1.1 & 0.5 & 0.9 & 0.9 & 2.9 & 1.4 & 0.5 & 1.5 & 4.2 & 1.5 & 1.7 & 3 & 3.7 & 1.9 \\
\hline $\mathrm{Rb}$ & 32.7 & 40.8 & 71.2 & 32.5 & 33.8 & 62.5 & 87 & 72.8 & 35.5 & 77.4 & 86.1 & 53.9 & 83.7 & 53 & 84.1 & 78.5 \\
\hline $\mathrm{Ba}$ & 680 & 620 & 742 & 481 & 608 & 722 & 936 & 1064 & 799 & 980 & 1250 & 525 & 665 & 2023 & 335 & 560 \\
\hline $\mathrm{Sr}$ & 341.8 & 534.7 & 529.4 & 709.5 & 414.4 & 613.6 & 214.7 & 213.4 & 629.6 & 185.4 & 225.9 & 155.4 & 234 & 237.6 & 95.3 & 141.2 \\
\hline $\mathrm{Ta}$ & 0.3 & 0.2 & 0.2 & 0.2 & 0.3 & 0.2 & 0.7 & 0.4 & 0.3 & 0.4 & 0.5 & 0.6 & 0.7 & 0.4 & 0.6 & 0.8 \\
\hline $\mathrm{Nb}$ & 3.5 & 2.7 & 2.7 & 2.9 & 4.8 & 4.1 & 7.7 & 4.9 & 4.3 & 4.7 & 7.2 & 8.5 & 10.6 & 9.4 & 7.8 & 9.1 \\
\hline $\mathrm{Hf}$ & 2.3 & 2.1 & 2.2 & 2.2 & 3.3 & 2.8 & 3.5 & 2.4 & 2.1 & 3.7 & 2.8 & 4.9 & 5.1 & 5.2 & 3.1 & 4.9 \\
\hline $\mathrm{Zr}$ & 76.5 & 76.5 & 76.8 & 77.5 & 118 & 107.3 & 106.4 & 101.9 & 91.1 & 115.2 & 113.9 & 188.2 & 181 & 195.6 & 116.7 & 168.1 \\
\hline $\mathrm{Y}$ & 16.5 & 14.3 & 15.6 & 19.8 & 16.2 & 17 & 20.1 & 14.7 & 10.8 & 15.5 & 16 & 18.1 & 26.1 & 20.8 & 17.9 & 29.7 \\
\hline Th & 6.7 & 4.9 & 6 & 2.2 & 8.6 & 6.7 & 13.3 & 10.2 & 5.1 & 11 & 11.7 & 7.3 & 10.4 & 7.5 & 15.3 & 11.5 \\
\hline $\mathrm{U}$ & 2.2 & 1.3 & 1.8 & 0.6 & 2.8 & 1.8 & 3.6 & 2.3 & 1.2 & 2.3 & 3.3 & 2.3 & 3.4 & 2.5 & 4.4 & 3.1 \\
\hline $\mathrm{La}$ & 17.7 & 16.5 & 19.9 & 14.6 & 27 & 21 & 27.5 & 25.8 & 20 & 23.7 & 28.2 & 21.5 & 28.7 & 25.7 & 30.5 & 30.1 \\
\hline $\mathrm{Ce}$ & 30.3 & 27.6 & 35.9 & 28.6 & 49.7 & 39.9 & 51.6 & 42.5 & 35.5 & 40.4 & 49.5 & 44.1 & 54 & 44.1 & 51 & 53.1 \\
\hline $\operatorname{Pr}$ & 3.43 & 3.23 & 4.06 & 3.49 & 5.5 & 4.52 & 5.62 & 4.58 & 4.02 & 3.98 & 4.93 & 4.68 & 6.04 & 4.99 & 5.12 & 6.17 \\
\hline $\mathrm{Nd}$ & 14.1 & 12.7 & 15.3 & 15.9 & 21.3 & 19.1 & 20.7 & 15.9 & 15.2 & 15.3 & 19.2 & 17.9 & 23.7 & 18.4 & 17.9 & 22.5 \\
\hline $\mathrm{Sm}$ & 3.05 & 2.68 & 3.4 & 3.03 & 4.19 & 3.83 & 4.31 & 2.94 & 2.8 & 2.47 & 3.12 & 3.89 & 4.73 & 3.75 & 2.98 & 4.9 \\
\hline $\mathrm{Eu}$ & 0.87 & 0.82 & 1.02 & 1.05 & 1.1 & 0.97 & 1.09 & 0.65 & 0.85 & 0.79 & 0.99 & 1.19 & 1.14 & 1.51 & 0.65 & 1.16 \\
\hline $\mathrm{Gd}$ & 3.12 & 2.63 & 3.38 & 3.26 & 3.99 & 3.39 & 4 & 2.71 & 2.24 & 2.68 & 3 & 3.9 & 4.48 & 4.13 & 2.28 & 4.88 \\
\hline $\mathrm{Tb}$ & 0.47 & 0.37 & 0.45 & 0.5 & 0.6 & 0.47 & 0.62 & 0.45 & 0.32 & 0.4 & 0.46 & 0.59 & 0.74 & 0.61 & 0.43 & 0.81 \\
\hline Dy & 3.2 & 2.49 & 3 & 3.48 & 3.3 & 2.93 & 3.69 & 2.52 & 1.78 & 3 & 2.7 & 3.18 & 4.43 & 3.69 & 2.47 & 4.84 \\
\hline Ho & 0.62 & 0.49 & 0.54 & 0.73 & 0.65 & 0.6 & 0.78 & 0.6 & 0.32 & 0.51 & 0.61 & 0.77 & 1.01 & 0.78 & 0.61 & 1.04 \\
\hline $\mathrm{Er}$ & 1.82 & 1.29 & 1.43 & 2.02 & 1.86 & 1.79 & 2.27 & 1.63 & 0.97 & 1.74 & 1.84 & 2.11 & 3 & 2.27 & 1.72 & 2.88 \\
\hline $\mathrm{Tm}$ & 0.26 & 0.19 & 0.21 & 0.29 & 0.27 & 0.24 & 0.33 & 0.32 & 0.14 & 0.26 & 0.32 & 0.3 & 0.45 & 0.36 & 0.28 & 0.45 \\
\hline $\mathrm{Yb}$ & 1.8 & 1.28 & 1.55 & 1.92 & 1.75 & 1.73 & 2.23 & 2.31 & 1.05 & 1.9 & 1.99 & 1.75 & 2.75 & 2.28 & 1.98 & 3.21 \\
\hline $\mathrm{Lu}$ & 0.28 & 0.21 & 0.24 & 0.28 & 0.27 & 0.26 & 0.35 & 0.34 & 0.15 & 0.3 & 0.32 & 0.31 & 0.45 & 0.37 & 0.33 & 0.49 \\
\hline$\overline{\mathrm{Mg} \#}$ & 26.58 & 38.59 & 36.38 & 33.08 & 26.42 & 30.17 & 28.59 & 38.74 & 34.86 & 26.77 & 20.73 & 9.33 & 18.82 & 9.94 & 20.24 & 18.36 \\
\hline $\mathrm{K}_{2} \mathrm{O} / \mathrm{Na}_{2} \mathrm{O}$ & 0.72 & 0.86 & 0.72 & 0.37 & 0.73 & 0.97 & 1.19 & 1.04 & 0.43 & 1.09 & 1.28 & 0.58 & 0.74 & 0.69 & 0.73 & 0.81 \\
\hline $\mathrm{Sr} / \mathrm{Y}$ & 20.72 & 37.39 & 33.94 & 35.83 & 25.58 & 36.09 & 10.68 & 14.52 & 58.3 & 11.96 & 14.12 & 8.59 & 8.97 & 11.42 & 5.32 & 4.75 \\
\hline$\left(\mathrm{La}_{N} / \mathrm{Lu}_{\mathrm{N}}\right)$ & 6.55 & 8.14 & 8.59 & 5.4 & 10.35 & 8.36 & 8.14 & 7.86 & 13.81 & 8.18 & 9.12 & 7.18 & 6.6 & 7.19 & 9.57 & 6.36 \\
\hline $\mathrm{Eu}=\mathrm{Eu} / \mathrm{Eu}^{*}$ & 0.85 & 0.93 & 0.91 & 1.02 & 0.81 & 0.81 & 0.79 & 0.69 & 1.01 & 0.93 & 0.98 & 0.92 & 0.75 & 1.17 & 0.73 & 0.72 \\
\hline
\end{tabular}

LOI (loss on ignition=ateşte kayıp):Toplam uçucu içeriği. $\mathrm{Mg} \#=100 \mathrm{xMgO} /\left(\mathrm{MgO}+\mathrm{Fe}_{2} \mathrm{O}_{3}{ }^{\mathrm{T}}\right) . \quad \mathrm{A} / \mathrm{CNK}=\quad \mathrm{Mol}$ $\mathrm{Al}_{2} \mathrm{O}_{3} /\left(\mathrm{CaO}+\mathrm{NaO}+\mathrm{K}_{2} \mathrm{O}\right) . \mathrm{Fe}_{2} \mathrm{O}_{3}{ }^{\mathrm{T}}$ : Toplam demir, $\mathrm{Eu}^{*}=(\mathrm{Sm}+\mathrm{Gd})_{\mathrm{N}} / 2$

$\mathrm{SiO}_{2}$ 'ye karşı $\left(\mathrm{Na}_{2} \mathrm{O}+\mathrm{K}_{2} \mathrm{O}\right)$ diyagramında ( $\mathrm{Le}$ Maitre vd., 1989), Mescitli volkanitlerinin subalkalen karakterli bazaltik andezit, bazaltik traki-andezit, andezit, traki-andezit, dasit ve riyolit bileşimli kayaçlardan oluştuğu görülür (Şekil 4a). Winchester ve Floyd (1977)'un $\mathrm{Nb} / \mathrm{Y}^{\prime}$ ye karş1 $\mathrm{Zr} / \mathrm{TiO}_{2}{ }^{*} 0.0001$ kimyasal adlandırma diyagramında volkanik kayaçlar 
andezit/bazalt, andezit ve riyolit/dasit bileşimli kayaçlardan oluşur (Şekil 4b). Winchester ve Floyd (1977)'un $\mathrm{SiO}_{2}-\mathrm{Zr} / \mathrm{TiO}_{2}$ diyagramında örneklerin genelde andezit ve dasit, az oranda da bazalt ve riyolit bileşimli kayaçlardan oluştuğu görülür (Şekil 4c). AFM diyagramında, sınıra düşen B11 nolu 1 örnek (bazaltik andezit) hariç, örneklerin tümü kalkalkalen karakterlidir (Şekil 4d).
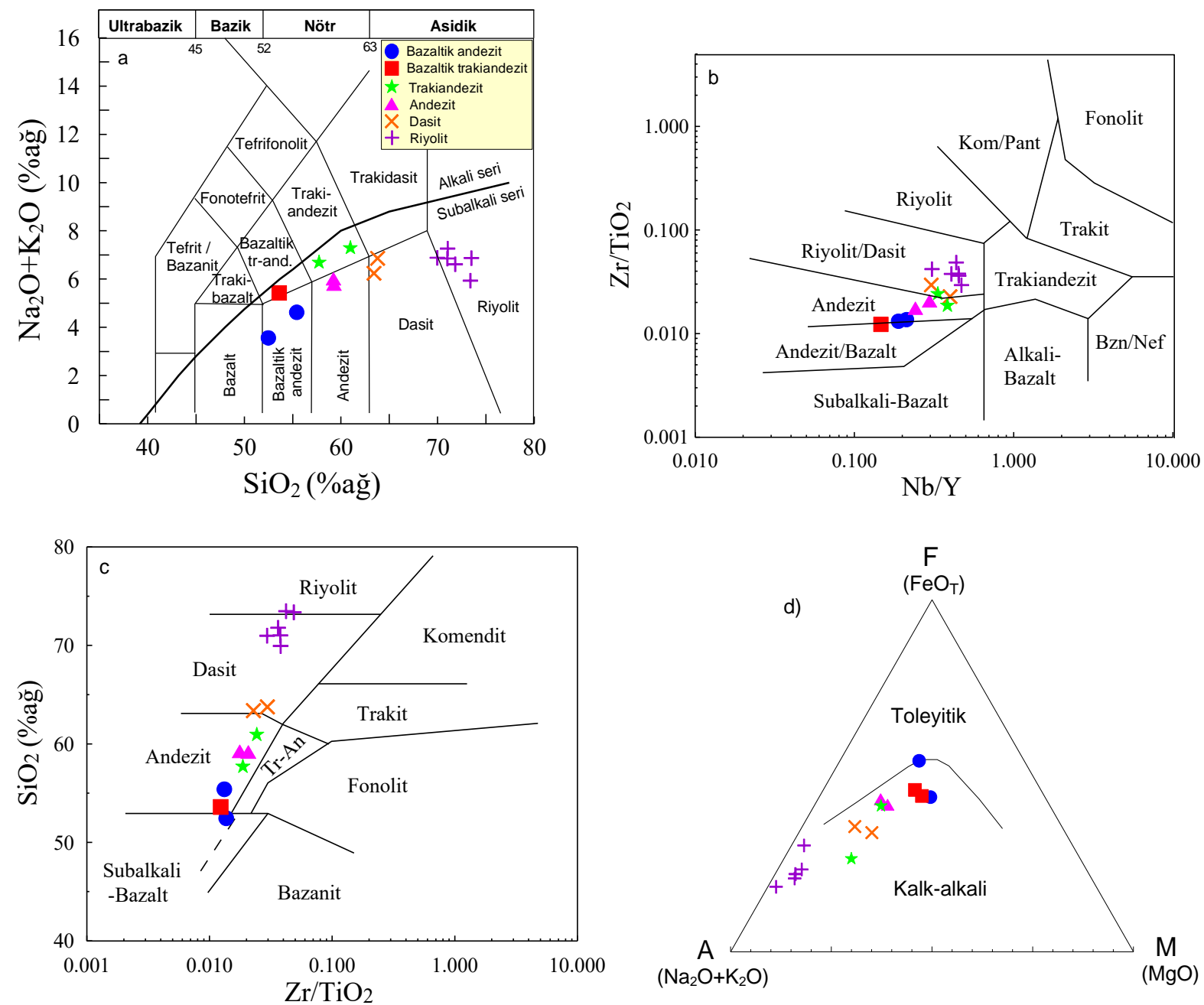

Şekil 4. Mescitli volkanitlerine ait örneklerin a) $\mathrm{SiO}_{2}$ 'e karşı toplam alkali $\left(\mathrm{Na}_{2} \mathrm{O}+\mathrm{K}_{2} \mathrm{O}\right)$ diyagramı (Le Maitre vd., 1989) (Alkali/Subalkali ayrımı eğrisi Irvine ve Baragar, 1971'den alınmıştır), b) $\mathrm{Nb} / \mathrm{Y}$ 'e karşı $\mathrm{Zr} / \mathrm{TiO}_{2}$ sınıflama diyagramı (Winchester ve Floyd, 1977), c) $\mathrm{SiO}_{2}-\mathrm{Zr} / \mathrm{TiO}_{2}$ diyagramı (Winchester ve Floyd, 1977), d) AFM diyagramı (Toleyitik-kalk alkali ayrımı eğrisi Irvine ve Baragar, 1971’den alınmıştır)

Kayaç örnekleri $\mathrm{K}_{2} \mathrm{O}-\mathrm{SiO}_{2}$ diyagramına (Le Maitre, 1989 ve Rickwood, 1989) düşürüldüğ̈̈nde, andezit, trakiandezit, bazaltik andezit ve bazaltik traki-andezitlere ait örneklerin yüksek potasyum; dasit ve riyolite ait örnekler ise orta-yüksek potasyum içeriğine sahip oldukları görülür (Şekil 5a).
$\mathrm{SiO}_{2}$ 'ye karşı ana ve iz element değişim diyagramlarının (Şekil 5 ve 6) bir kısmında düzensiz dağılımlar gözlenmekle birlikte, yer yer iyi korelasyonlar vermeleri, Eosen yaşlı volkanitlerin gelişiminde ayrımlaşmanın oldukça önemli bir rol oynadığına işaret etmektedir. $\mathrm{SiO}_{2}$ 'ye karşı ana element değişim diyagramlarında; $\mathrm{SiO}_{2}$ değerleri 
arttıça $\mathrm{CaO}, \mathrm{MgO}$ ve $\mathrm{Fe}_{2} \mathrm{O}_{3}{ }^{\mathrm{T}}$ azalarak iyi derecede negatif bir ilişki gösterirler (Şekil 5c-e). $\mathrm{Al}_{2} \mathrm{O}_{3}, \mathrm{P}_{2} \mathrm{O}_{5}$ ve $\mathrm{TiO}_{2}$ 'de $\mathrm{SiO}_{2}$ arttıkça çok iyi olmasa da yine negatif bir ilişki görülür. $\mathrm{K}_{2} \mathrm{O}$ ve $\mathrm{Na}_{2} \mathrm{O}$ değerlerinde ise $\mathrm{SiO}_{2}$ artışına paralel olarak pozitif bir korelasyon gözlenir (Şekil 5a ve b).
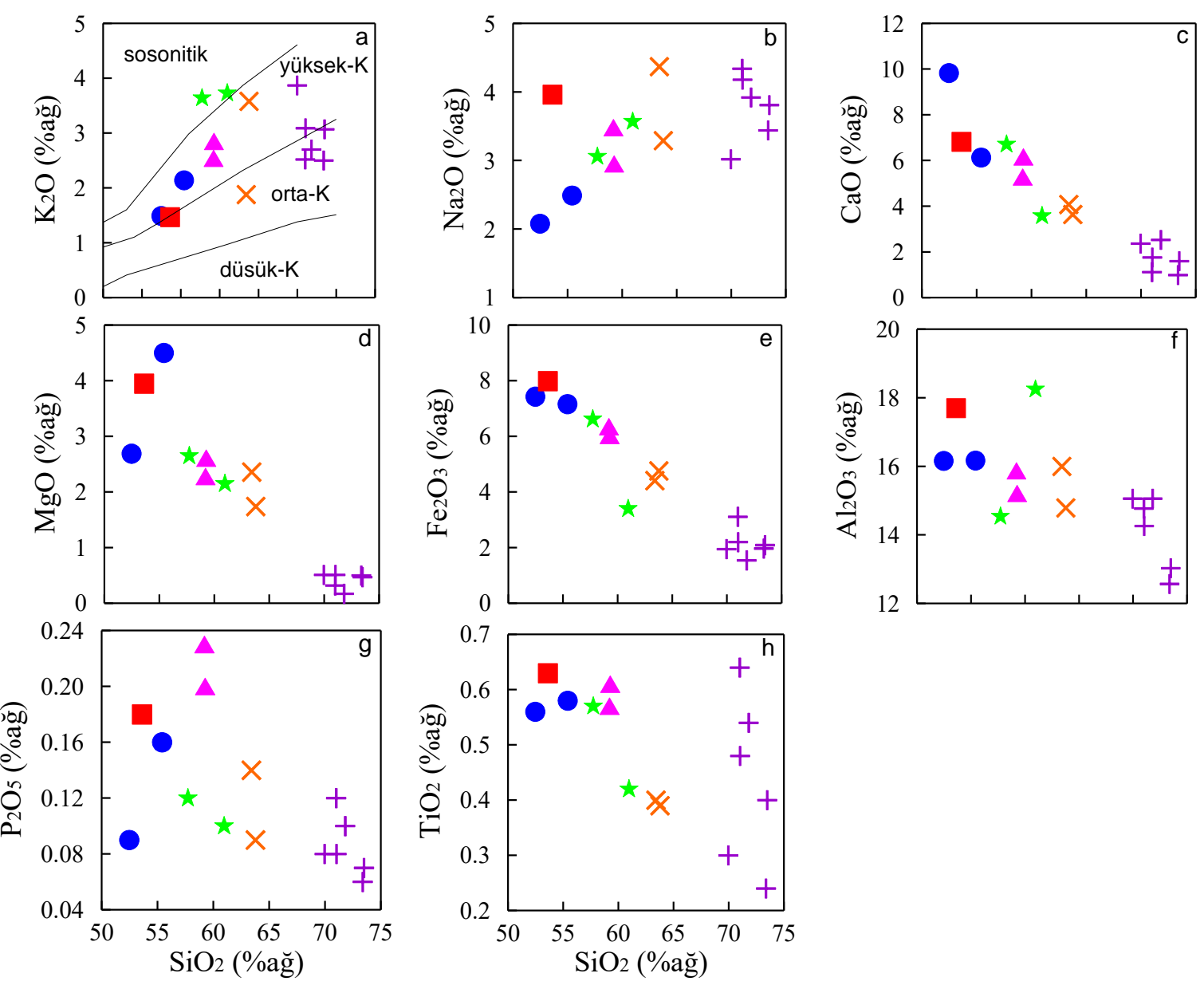

Şekil 5. Mescitli volkanitlerine ait kayaç örneklerinin $\mathrm{SiO}_{2}$ 'ye karşı ana element değişim diyagramları ( $\mathrm{SiO}_{2}$ 'e karşı $\mathrm{K}_{2} \mathrm{O}$ diyagramı Le Maitre vd., 1989'dan alınmıştır) (Semboller Şekil 4a'daki gibidir)

$\mathrm{SiO}_{2}$ 'ye karşı iz element değişim diyagramlarında; $\mathrm{SiO}_{2}$ arttıkça $\mathrm{Zr}, \mathrm{Ba}, \mathrm{Rb}, \mathrm{Nb}$ ve Th değerlerinde pozitif bir ilişki gözlenirken; Sr ve Ni'de negatif bir ilişski gözlenir (Şekil 6a-h). Y değerlerinde ise riyolitlerde pozitif, diğer kayaç türlerinde ise negatif bir ilişki gözlenir (Şekil 6).

Örneklerin ilksel mantoya (Sun ve McDonough, 1989) göre normalleştirilmiş olan iz element değișim diyagramında $\mathrm{Sr}, \mathrm{K}$, $\mathrm{Rb}, \mathrm{Ba}, \mathrm{Th}, \mathrm{U}, \mathrm{Pb}$ ve $\mathrm{Nd}$ konsantrasyonları bakımından zenginleşme gözlenirken; $\mathrm{Ti}, \mathrm{Nb}$, $\mathrm{Ce}, \mathrm{Pr}, \mathrm{P}$ ve Ta bakımından fakirleşme izlenmektedir (Şekil 7a-g). Özellikle Th, U ve $\mathrm{Rb}$ gibi elementlerdeki zenginleşme kabuk etkisini yansitmaktadir. Negatif $\mathrm{Nb}$ ve Ta anomalisi, kayaçların ana magmasının gelişiminde, yitim bileşeninin etken bir rol oynadığını göstermektedir. 

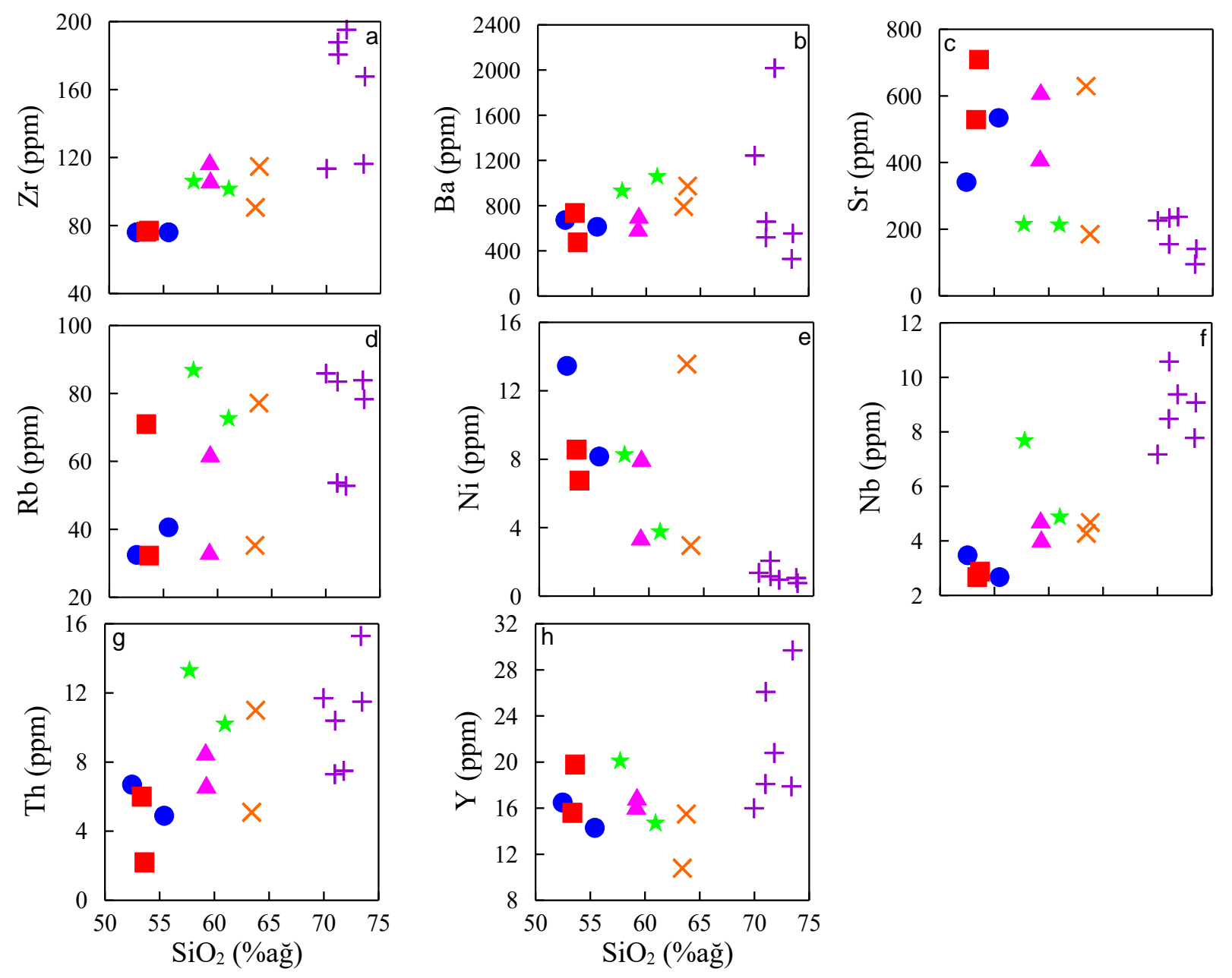

Şekil 6. Mescitli volkanitlerine ait kayaç örneklerinin $\mathrm{SiO}_{2}$ 'ye karşı iz element değişim diyagramları (Semboller Şekil 4a'daki gibidir)

Bölgede Eosen yaşlı volkanik kayaçlar üzerine yapılan çalışmalar dikkate alındığında, incelenen volkanik kayaçların iz element içerikleri Eosen yaşlı Torul volkanitleri (Kaygusuz vd., 2011a) ve Kale volkanitleri (Aliyazıcıŏlu, 1999)'ne benzer yönsemeler gösterirler (Şekil 7g).

İncelenen volkanitlerin kondrite (Taylor ve McLennan, 1985) normalize edilmiş nadir toprak element (NTE) dağılımları genel olarak birbirine benzerlik göstermektedir (Şekil 8a-g). Bu durum, inceleme alanındaki volkanitleri oluşturan kayaçların benzer manto kaynağından türediklerini işaret etmektedir. Volkanik kayaç örneklerinin kondrite normalize edilmiş nadir toprak element dağılım diyagramlarında (Şekil 8), hafif nadir toprak elementler, ağır nadir toprak elementlere göre daha fazla zenginleşmiştir. Örneklerin $(\mathrm{La} / \mathrm{Lu})_{\mathrm{N}}$ oranları 5.4-13.81 arasında değişir (Tablo 1).

Örneklerin hemen hemen tümünde negatif $\mathrm{Eu}$ anomalisi gözlenmemekte olup (Şekil 8), $\left(\mathrm{Eu} / \mathrm{Eu}^{*}\right)_{\mathrm{N}}$ oranları 0.7-1.1 arasındadır (Tablo $1)$.

Bölgede Eosen yaşlı volkanik kayaçlar üzerine yapılan çalışmalarla karşılaştırıldığında, incelenen volkanik kayaçların nadir toprak element içerikleri Kale volkanitleri (Aliyazıcığlu, 1999) ve Torul volkanitlerine (Kaygusuz vd., 2011) benzer yönsemeler göstermekle birlikte, onlara nazaran hafif nadir toprak elementlerce biraz zenginleşmişlerdir (Şekil 8g). 

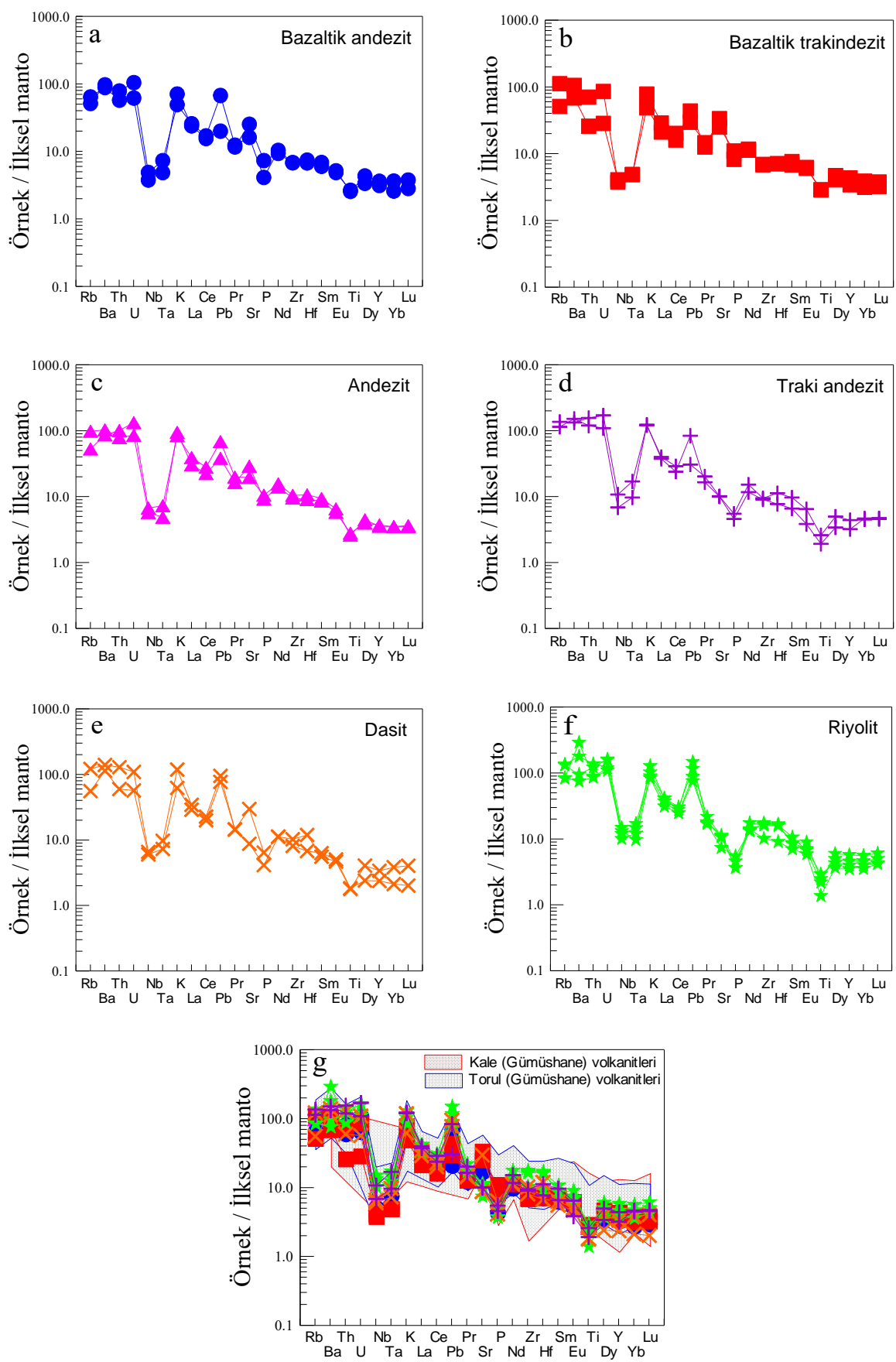

Şekil 7. Mescitli volkanitlerine ait kayaçların ilksel mantoya göre (Sun ve McDonough, 1989) normalize edilmiş iz element dağılım diyagramları (Semboller Şekil 4a'daki gibidir)

\subsection{Tektonik Konum}

İnceleme alanındaki volkanitlerin değişim diyagramlarına bakıldığında, iz element değişimlerinde $\mathrm{Nb}$, Ta, $\mathrm{Zr}$ ve Ti bakımından tüketilme, $\mathrm{Sr}, \mathrm{K}, \mathrm{Ba}, \mathrm{Rb}$ ve HNTE bakımından bir zenginleşme görülmekte olup, bu değerler volkanitlerin magmasının bir yitim zonu ortamında geliştiğini göstermektedir (Pearce and Peate, 1995;
Turner, 2005). Volkanitlerin, okyanus ortas sirtı bazaltları, okyanus adası bazaltları ve plaka içi bazaltlarından daha yüksek $\mathrm{Ba} / \mathrm{La}$ (10.98-44.33) ve daha düşük $\mathrm{Nb} / \mathrm{La}$ (0.140.40 ) oranlariyla (Tablo 1) orojenik volkanik kayaçlara benzerlik gösterirler (Sun ve McDonough, 1989).

İncelenen volkanitlerin, alterasyondan fazla etkilenmediği bilinen $\mathrm{Ti}, \mathrm{Zr}, \mathrm{Sr}$ ve $\mathrm{Nb}$ gibi 
elementlerin birbirleriyle ilişkilerine göre tektonik ortamları belirlenmeye çalıșılmıștır. Nb'ye karş1 Nb/Th (Pearce ve Cann, 1973) tektonik ayırtman diyagramına göre, örnekler yay volkanitleri alanına ve yakın yerlere düşmektedir (Şekil 9a). Sr/Y-Y (Defant ve Drummond, 1990) ayırtman diyagramında örnekler normal yay volkanik serisi alanına düşmektedir (Şekil 9b).
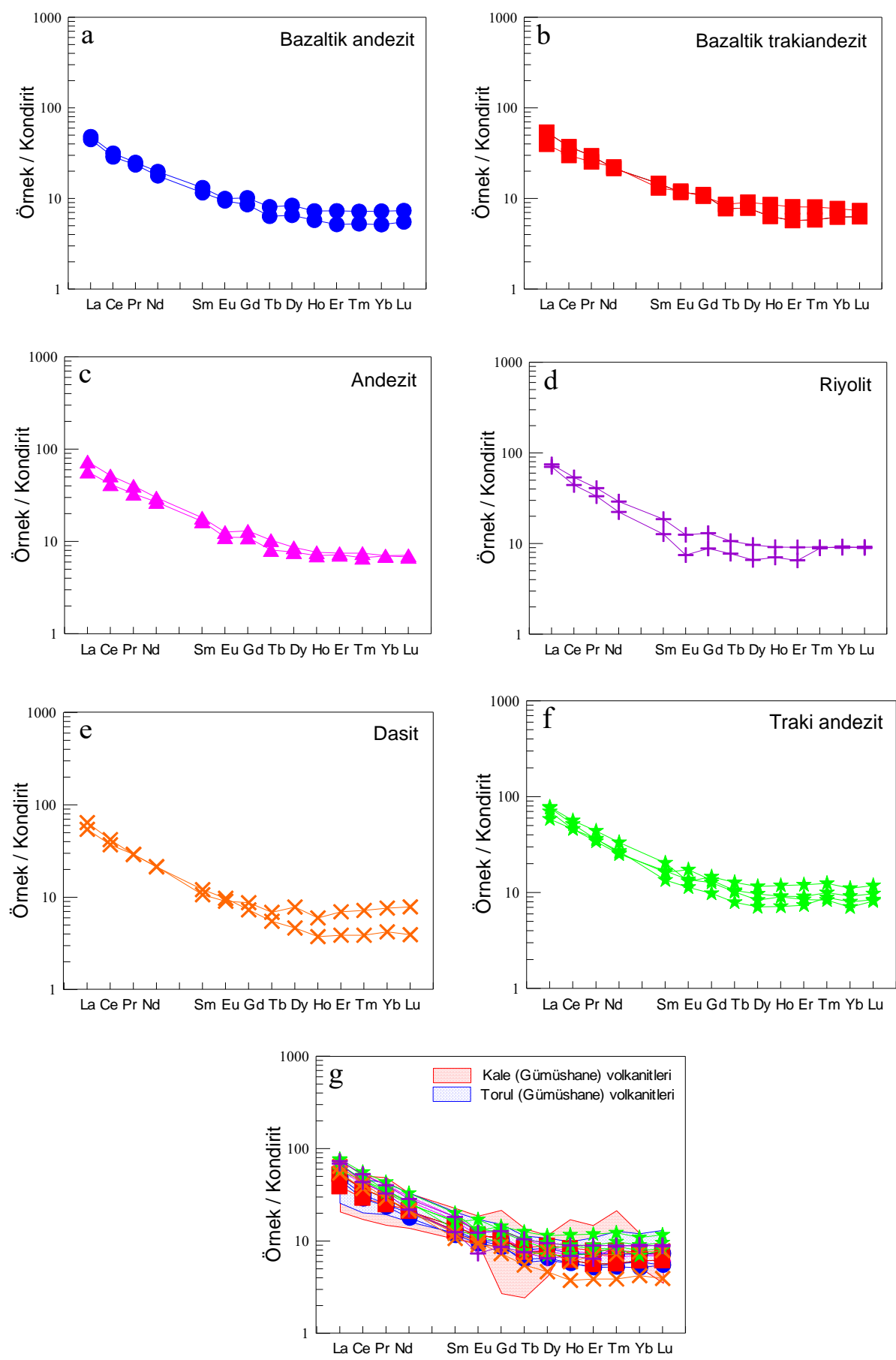

Şekil 8. Mescitli volkanitlerine ait kayaçların kondirite (Taylor ve McLennan, 1985) normalize edilmiş nadir toprak element dağılımları (Semboller Şekil 4a'daki gibidir) 

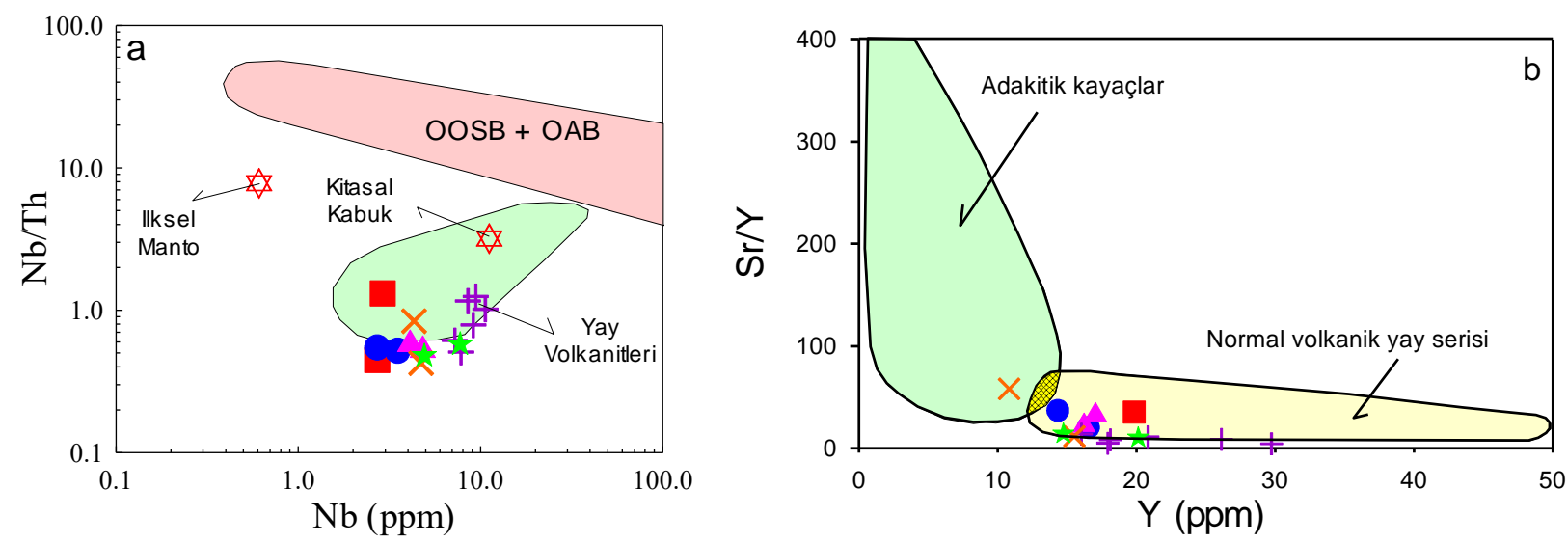

Şekil 9. Mescitli volkanitlerine ait tektonik ayırtman diyagramları. (a) $\mathrm{Nb}$ (ppm)'ye karşı $\mathrm{Nb} / \mathrm{Th}$ diyagramı (ilksel manto değerleri Hoffmann, 1988'den, kıtasal bazalt-OOSB+OAB ve yay volkanitleri alanları Schmidberger ve Hegner, 1999'den alınmıştır). (b) Sr/Y-Y ayırtman diyagramı (Defant ve Drummond, 1990) (Semboller Şekil 4a’daki gibidir)

İncelen volkanitler Ba'a karşı $\mathrm{Nb}$ ve $\mathrm{La}$ (Perfit vd., 1980; Gill, 1981) tektonik ortam ayırtman diyagramlarda (Şekil 10a ve b), yüksek Ba/La (10.98-78.72) ve $\mathrm{Ba} / \mathrm{Nb}$ (61.76274.81) oranları ile orojenik andezitlere benzerlik gösterirler. Ancak, bu diyagramda riyolitler diğer birimlere kıyasla daha yüksek, bazaltik trakiandezitler ise daha düşük $\mathrm{Ba}, \mathrm{Nb}$ ve La içeriğine sahiptir. Bu da benzer kökenli magma(lar)dan itibaren farklı ayrımlaşma süreçleri ile oluştuklarına işaret eder.
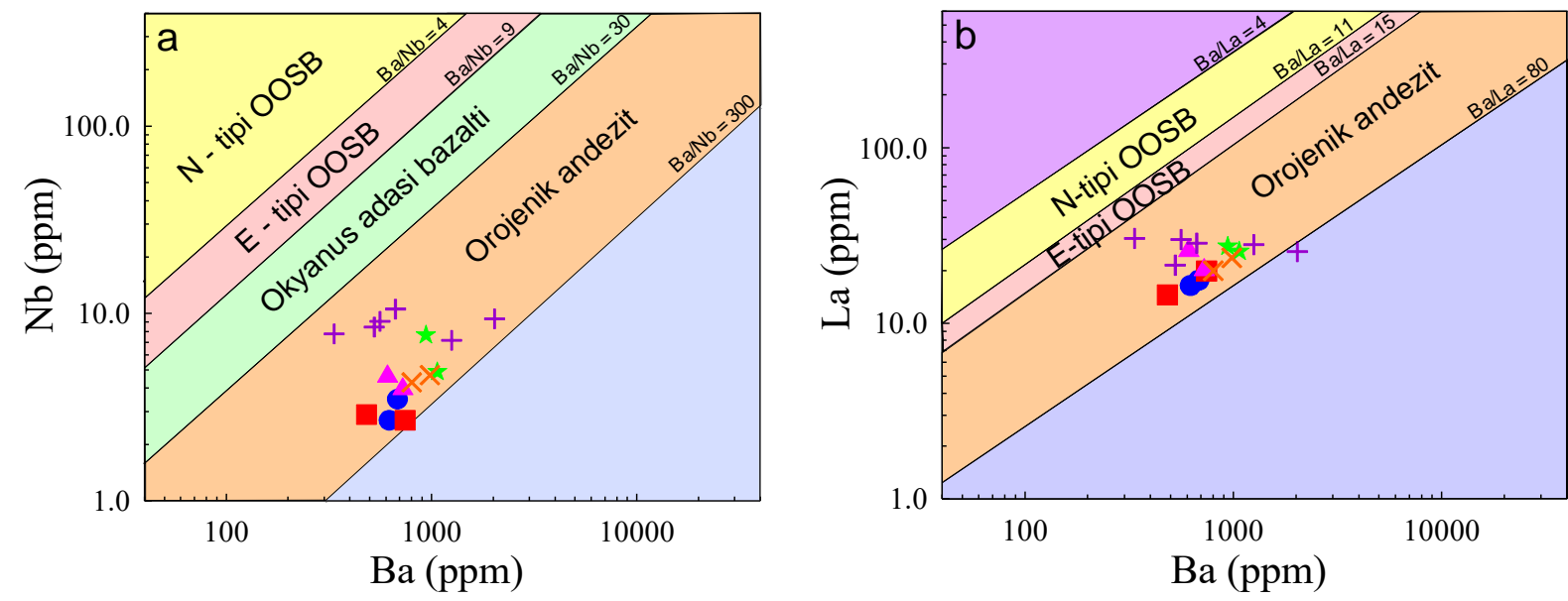

Şekil 10. Mescitli volkanitlerine ait, (a) Ba'ya karşı Nb ve b) Ba'ya karşı La tektonik ortam ayırtman diyagramları (Alanlar: Perfit vd.,1980 ve Gill, 1981'den) (OOSB: Okyanus ortası sırtı bazaltı) (Semboller Şekil 4a'daki gibidir)

\section{Tartışma}

\subsection{Ayrımlaşma}

Tüm kayaç ana, iz ve nadir toprak element verileri dikkate alındığında (Şekil 5 ve 6), volkanitlerin gelişiminde klinopiroksen, plajiyoklas ve Fe-Ti oksit ayrımlaşmasının önemli olduğu görülür. Artan $\mathrm{SiO}_{2}$ içeriğine karşıllık $\mathrm{TiO}_{2}$ ve $\mathrm{Fe}_{2} \mathrm{O}_{3}{ }^{\mathrm{T}}$ içeriklerinin giderek azalması $\mathrm{Fe}-\mathrm{Ti}$ oksitlerin ayrımlaşmasına işaret etmektedir. $\mathrm{SiO}_{2}$ 'ye karş $1 \mathrm{CaO}, \mathrm{Fe}_{2} \mathrm{O}_{3}{ }^{\mathrm{T}}$ ve $\mathrm{MgO}$ daki negatif ilişkiler plajiyoklas $(A n>50)$ ve klinopiroksen fazların ana magmadan ayrımlaştığına işaret etmektedir. $\mathrm{SiO}_{2}$ 'e karşı $\mathrm{Fe}_{2} \mathrm{O}_{3}{ }^{\mathrm{T}}$ ve $\mathrm{Al}_{2} \mathrm{O}_{3}$ deki birliktelikli 
azalan negatif ilişki hornblend ayrışmasına işaret etmektedir. $\mathrm{SiO}_{2}$ 'e karş1 $\mathrm{K}_{2} \mathrm{O}$ ve $\mathrm{Na}_{2} \mathrm{O}$ diyagramlarında dağınık olmakla birlikte pozitif ilişkiler söz konusudur. Bu dağınıklık alterasyon olaylarının kısmen etkili olduğunu ve pozitif ilişkinin de bazik plajiyoklasların giderek ayrımlaştığını ifade etmektedir. $\mathrm{SiO}_{2}$ 'ye karşı $\mathrm{P}_{2} \mathrm{O}_{5}$ değişim diyagramında gözlenen negatif korelasyon ise apatit fraksiyonlaşmasını yansıtmaktadır (Şekil 5). $\mathrm{SiO}_{2}$ 'e karşı $\mathrm{Ni}$ azalması, klinopiroksen ayrımlaşmasını desteklemektedir. $\mathrm{SiO}_{2}$ ile $\mathrm{Zr}$ arasındaki pozitif ilişki manyetit ve hornblend ayrımlaşmasını göstermektedir. $\mathrm{Ba}, \mathrm{Rb}$, Th elementleri genellikle feldispatlar ve hornblendlerin bünyesine girdikleri ve ayrımlaşma sırasında geç evrelerde kristallendikleri için pozitif bir ilişki göstermektedirler (Şekil 6).

Genel olarak, kayaçların kondrite normalize edilmiş nadir toprak element dağılımlarında hafif nadir toprak elementlerin, orta ve ağır nadir toprak elementlere göre daha fazla zenginleşmesi, nadir toprak element dağılım diyagramında konkav bir yap1 sunmas1, volkanik kayaçların gelişiminde klinopiroksen ve hornblend ayrımlaşmasının etkili olduğunu göstermektedir (Fujimaki vd., 1984) (Şekil 6). Y'a karşı CaO diyagramında (Şekil 11), Eosen yaşlı andezitik kayaçlar hemen hemen dikey ve L-tipi bir yönseme göstermekte olup, plajiyoklas ve klinopiroksen ağırlıklı ayrımlaşmanın etkili olduğunu ifade eder.

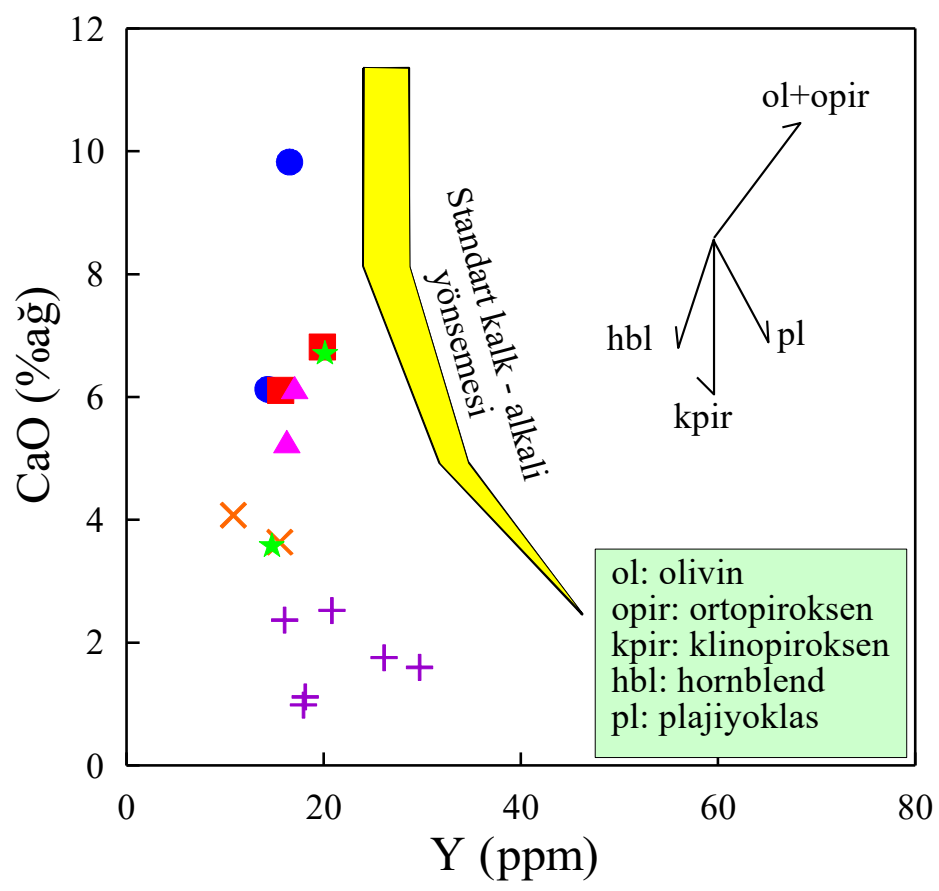

Şekil 11. Mescitli volkanitlerin Y (ppm)'a karşı CaO (\%) diyagramı (Lambert ve Holland, 1974), Vektörler, bazaltik bileşim için minerallerin ayrımlaşma yönlerini göstermektedir (Semboller Şekil 4a'daki gibidir)

\section{2. Özümleme}

Kabuksal materyallerin asimilasyonu, mantodan türeyen kayaçların iz element ve izotopik bileşimlerini etkileyen önemli bir süreçtir (McDermott vd., 2005; Zellmer vd., 2005). Doğu Pontidler'de Paleojen ve Neojen yaşlı çarpışma ve çarpışma sonrası volkanik kayaçlar üzerine yapılan çalışmalarda (Temizel ve Arslan 2008, 2009; Kaygusuz vd., 2011a; Temizel vd., 2012; Arslan vd., 2013; Yücel, 2013; Aydınçakır, 2014) birincil magmanın olgun ve kalınlaşmış kabuk tarafından kirlenmesinin önemli bir özellik olduğunu vurgulamışlardır. $\mathrm{Bu}$ nedenle, mantodan türeyen kayaçların kabuktan 
yükselirken olasılı kabuksal kirlenmeye uğraması ve bunun magma bileşimine etkisi, çalışılan volkanitlerin kaynak bileşimlerinin karakterlerini belirlemede değerlendirilebilir.

$\mathrm{SiO}_{2}$ 'ye karşı $\mathrm{Y} / \mathrm{Nb}$ oranlarında gözlenen negatif yönsemeler, magma gelişimi esnasında kabuksal özümlemeye işaret eder (Şekil 12a). Th/Yb ve Ta/Yb oranları, kaynak bileşimi ve kabuksal kirlenmenin tayininde etkili bir şekilde kullanılması, kabuksal kirlenmede $\mathrm{Ta}$ ve Yb'ye nazaran Th elementinin daha fazla etkilenmesinden kaynaklanmaktadır (Pearce vd., 1990). $\mathrm{Th} / \mathrm{Yb}$ 'ye karşı $\mathrm{Ta} / \mathrm{Yb}$ diyagramı (Şekil 12b), incelenen kayaçların gelişiminde AFC proseslerinin önemli bir rol oynadığını ve volkanitlerin oluşumuna kaynaklık eden magmanın ilksel mantoya göre yitim zonu zenginleşmesine uğradığını gösterir.

\subsection{Kaynak Karakteristiği}

Mescitli volkanik kayaçlarında gözlenen LILE element ( $\mathrm{K}, \mathrm{Sr}, \mathrm{Rb}$ ve $\mathrm{Ba})$, Th ve $\mathrm{Ce}$ zenginleşmesi, yüksek $\mathrm{Th} / \mathrm{Yb}$ oranları, volkanitlerin ana magma(larının)sının litosferik manto kaynağından türemiş olabileceğini gösterir (Pearce ve Peate 1995; Churikova vd., 2001; Elburg vd., 2002; McDermott vd., 2005; Zellmer vd., 2005). Ayrıca, çalışılan volkanik kayaçlarda gözlenen LILE elementlere nazaran $\mathrm{Nb}$ ve $\mathrm{Ta}$ tüketilmesi, sedimentler yada yiten levhadan türeyen sivıların metazomatizmasıyla etkilenmiş, yitimle ilişkili magma kaynağının özelliğini ifade eder (Pearce 1983; Hawkesworth vd., 1997; Elburg vd., 2002). $\mathrm{Ce} / \mathrm{Pb}$ 'ye karşı Ce diyagramında (Şekil 13a), çalışılan volkanik kayaçlara ait örnekler yay volkanikleri alanında yer alırlar.
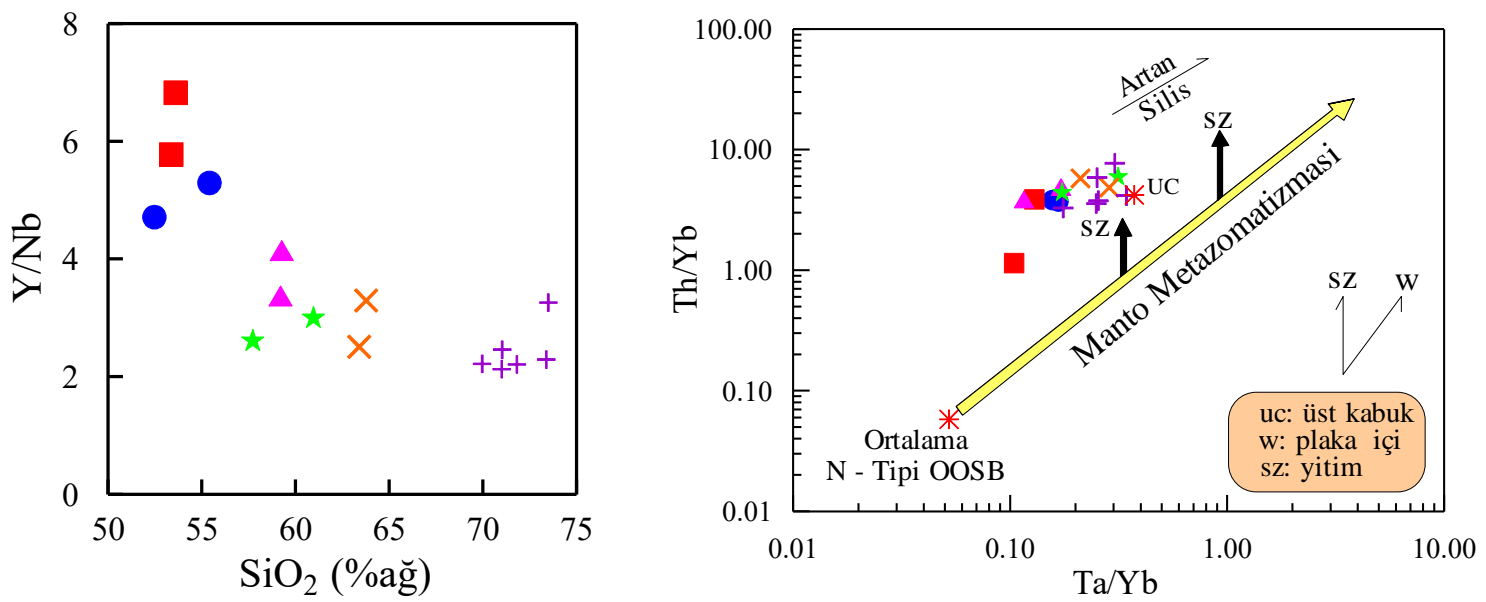

Şekil 12. Mescitli volkanitlerinin, a) $\mathrm{SiO}_{2}$ 'ye karşı $\mathrm{Y} / \mathrm{Nb}$ diyagramı, b) $\mathrm{Ta} / \mathrm{Yb}$ 'a karşı $\mathrm{Th} / \mathrm{Yb}$ diyagramı (Pearce vd., 1990), (yitim zenginleşmesi ve manto metasomatizmasını gösterir vektörler Pearce vd., 1990'dan alınmıştır, N-tipi OOSB ve ortalama üst kabuk değerleri Sun ve McDonough, 1989 ve Taylor and McLennan, 1985'ten alınmıştır) (Semboller Şekil 4a'daki gibidir)

Örneklerde gözlenen düşük $\mathrm{Ce} / \mathrm{Pb}$ oranları (1.8 ila 9.1), okyanusal bazaltlardan (20 ila 30) (Hoffmann, 1988, 1997) farklı olup, bu durum çalışılan volkanik kayaçların astenosferik manto kaynağından türemediğini gösterir. Yüksek Nb/La oranları $(>1)$ okyanus adası bazalt (OIB) benzeri astenosferik manto kaynağını, düşük oranlar $(<0.5)$ ise litosferik manto kaynağına işaret eder (Bradshaw and Smith, 1994; Smith vd., 1999). Bu nedenle, $\mathrm{Nb} / \mathrm{La}$ ve $\mathrm{La} / \mathrm{Yb}$ oranları volkanik kayaçlarda kısmı ergime derecesi ve kaynak bileşiminin belirlenmesinde faydalıdır (Jahn vd., 1999). İncelenen volkanik kayaçlarının $\mathrm{Nb} / \mathrm{La}$ oranları 0.14 ila 0.40 arasinda ve ortalama $\mathrm{La} / \mathrm{Yb}$ oranları 7.6 ila 19.1 arasinda olup (Tablo 1), spinel lerzolitik litosferik manto kaynağına işaret eder (Şekil 13b). İncelenen volkanik kayaçlar (Şekil 13c)'de yay volkanikleri alanında yada yakınında yer alırlar. Volkaniklerin $\mathrm{La} / \mathrm{Nb}$ (2.5 ila 7.4) ve $\mathrm{Ba} / \mathrm{Nb}$ (61 ila 274) oranlar1, yitim zonu 
zenginleşmesi ile ilgili kaynağı gösterir. Yitim anında, LILE ve LREE elementler slabdan türeyen sıvılar yoluyla yukariya doğru taşınırlar (Churikova vd., 2001; Elburg vd., 2002). Bu nedenle, çalışılan volkanitlerde gözlenen önemli LILE ve LREE zenginleşmeleri, tüketilmiş manto kaynağına nazaran, zenginleşmiş manto kaynağına işaret eder (Rogers vd., 2000; Condie vd., 2002; Zhao vd., 2006).

Pearce (1983) tarafindan önerilen $\mathrm{Th} / \mathrm{Y}$ 'ye karşı $\mathrm{Nb} / \mathrm{Y}$ diyagramı (Şekil 13d), ergime zenginleşmesi ürünleri ile yitim zenginleşmesi ürünü volkanik kayaçlarını ayırmada kullanılır. Ayrıca, $\mathrm{Th} / \mathrm{Y}$ ve $\mathrm{Nb} / \mathrm{Y}$ oranları kabuksal kirlenme ve magma kaynağındaki homojenleşmeyi ayırmada kullanılabilir. İncelenen volkanik kayaçları OAB ve OOSB çizgisine paralel trend gösterirler (Şekil 13d), ancak onlara nazaran daha yüksek $\mathrm{Th} / \mathrm{Y}$ oranlarına sahip olup, manto kaynağının yitim zonu sıvılarınca metasomatizmaya uğramasını ifade eder. $\mathrm{Th} / \mathrm{Yb}$ 'ye karşı $\mathrm{Ta} / \mathrm{Yb}$ diyagramında (Şekil 12b), volkanik kayaçlar manto dizinine paralel bir yönseme gösterirler, ancak daha yüksek $\mathrm{Th} / \mathrm{Yb}$ oranlarına sahiptirler. $\mathrm{Bu}$ yönseme, önceki (Eosen öncesi) yitim prosesleri yoluyla türemiş sıvıların zenginleştirdiği (metazomatizma) kaynaktan türeyen ana magma(lara)ya işaret eder.

İncelenen Eosen yaşlı Mescitli volkanitlerinin ana ve iz element karakteristikleri, Doğu Pontidler'deki diğer Paleojen ve Neojen yaşlı volkanik kayaçlara (Temizel ve Arslan, 2008; Kaygusuz vd., 2011; Temizel vd., 2012; Arslan vd., 2013; Yücel, 2013; Yücel vd., 2014) benzer olup, incelenen volkanitleri oluşturan ana magma(lar)nın, Eosen öncesinde yitimle ilişkili olaylardan türeyen sıvıların metazomatizması yoluyla etkilenen, yarı kıtasal litosferik manto kaynağından türemiş olabileceğini gösterir.

\section{Sonuçlar}

Mescitli volkanitlerini oluşturan andezit, dasit ve riyolit türü kayaçlar genellikle porfirik, hyalo-porfirik, glomeroporfirik, entersertal, entergranüler ve akma (flüidal) dokusu göstermekte olup, başlica mineraller plajiyoklas, alkali feldispat, kuvars, hornblend, ojit ve biyotit fenokristallerinden oluşur.

Değişim diyagramlarında gözlenen iyi derecede pozitif ve negatif ilişkiler, kayaçların gelişiminde ayrımlaşmanın etkili olduğunu ve klinopiroksen + plajiyoklas \pm hornblend \pm magnetit fraksiyonlaşmasının rol oynadığını göstermektedir. Volkanitlerin ilksel mantoya göre normalize edilmiş iz element dağılımları, özellikle büyük iyon yarıçaplı litofil element ve daha az oranda Th ve Ce konsantrasyonları bakımından zenginleşme, fakat $\mathrm{Zr}, \mathrm{Y}$ ve $\mathrm{TiO}_{2}$ konsantrasyonları bakımından fakirleşme göstermektedir. Bunun yanında, kayaçların azalan $\mathrm{Nb}$ ve Ta içerikleri volkanitlerin köken magmasının muhtemelen daha önceden akışkanlar tarafindan metasomatizmaya uğratılmış zenginleşmiş bir kaynak bölgeden (litosferik manto) türeyebileceklerini ifade etmektedir.

Kondrite göre normalize edilmiş nadir toprak element dağılımları, düşük-orta derecede zenginleşmeyle $\left(\mathrm{La}_{\mathrm{N}} / \mathrm{Lu}_{\mathrm{N}}=5.4\right.$ ila 13.8) konkav şekilli olup, genellikle birbirine paralel dağılım göstermeleri benzer kaynaktan itibaren oluştuğunu gösterir.

Tektonik ayırtman diyagramlarına göre, yüksek $\mathrm{Ta} / \mathrm{Yb}$ ve $\mathrm{Th} / \mathrm{Yb}$ içeriklerine sahip volkanitler, volkanik yay bazaltları alanına düşmektedirler. $\mathrm{Bu}$ veri, Mescitli volkanitlerinin oluşumuna kaynaklık eden magmanın, ilksel mantoya göre yitim zonu zenginleşmesine uğradığını ve bu kayaçların gelişiminde ayrımlaşmanın önemli bir rol oynadığını ifade etmektedir.

Mescitli yöresi Eosen yaşlı volkanitlerin mineralojik, petrografik ve jeokimyasal özellikleri dikkate alındığında, volkanitlerin köken magmasının muhtemelen daha önceki yitim akışkanları tarafından metasomatizmaya uğramış yarı kıtasal bir litosferik manto kaynağının kısmi ergimesi ile oluştuğunu ve daha sonra da kitasal kabuktaki sı̆̆ magma odalarının gelişimi ile ayrımlaşma \pm özümleme gibi magmatik olaylarla geliştiklerini göstermektedir. 

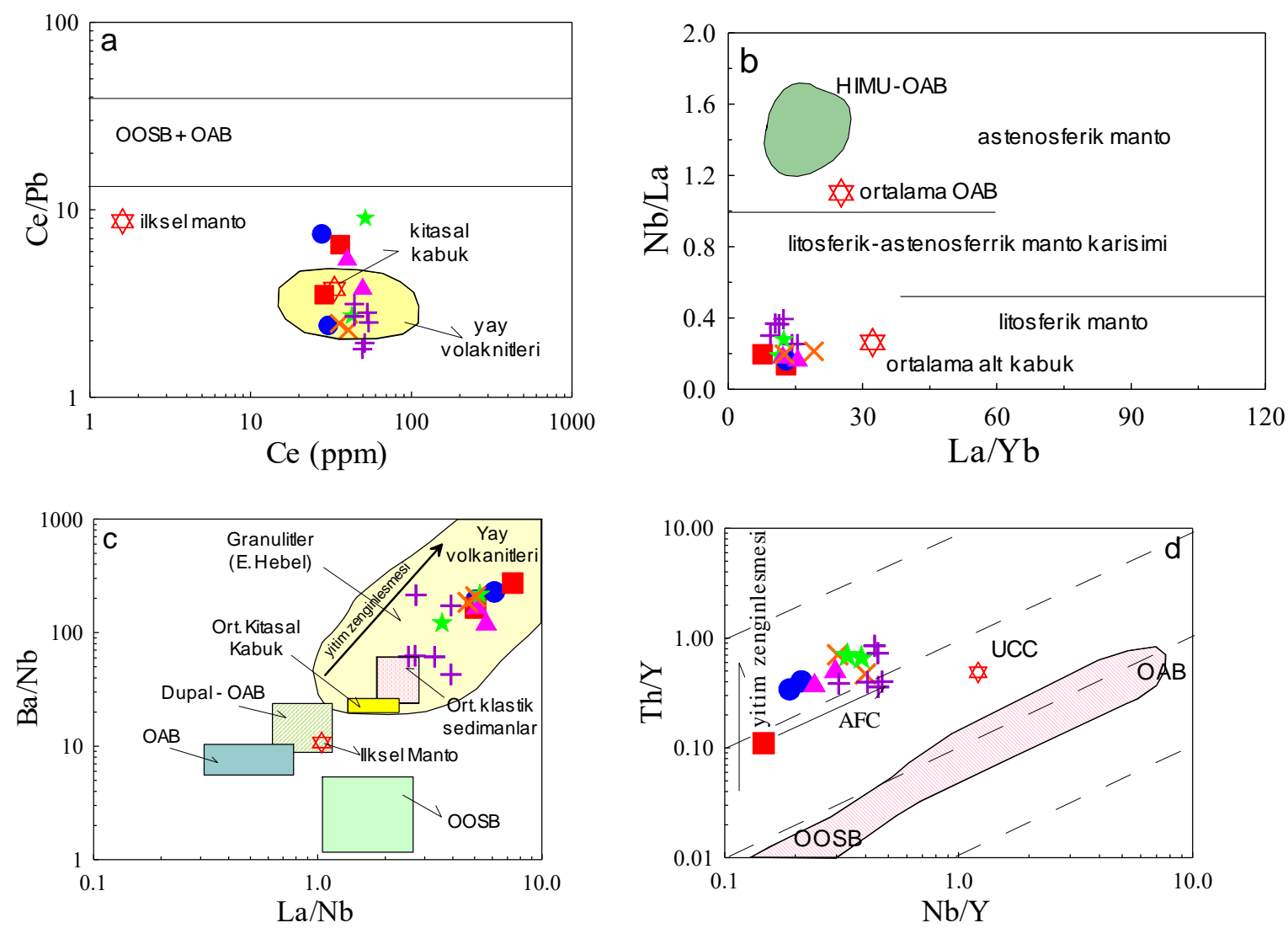

Şekil 13. Mescitli volkanitlerinin; (a) Ce/Pb karşı Ce diyagramı (ilksel manto değerleri Hofmann, 1988'den, kıtasal kabuk, OOSB, OAB ve yay volkanitleri Schmidberger ve Hegner, 1999'dan alınmıştır). (b) La/Yb'ye karşı Nb/La diyagramı (OAB değerleri, Fitton vd., 1991 'den, ortalama alt kabuk değerleri, Chen ve Arculus, 1995'den, HIMU+OAB alanlar1, Weaver vd., 1987'den, astenosferik, litosferik ve karışım manto alanlarını ayıran çizgi Smith vd., 1999'dan alınmıştır), (c) Ba/Nb'a karşı La/Nb diyagramı (Jahn vd., 1999) (Yay volkanitleri ve Arkeen granülitleri, Jahn ve Zhang, 1984'den, İlksel Manto, Sun ve McDonough, 1989'dan, ortalama Kitasal kabuk, Taylor ve Mclennan, 1985 ve Condie, 1993 'den, Dupal-OAB, Jahn vd., 1999'dan alınmıştır). (d) Th/Y'ye karşı Nb/Y diyagramı (Pearce, 1983) (Semboller Şekil 4a'daki gibidir)

\section{Teşekkürr}

$\mathrm{Bu}$ makalenin inceleme ve değerlendirme aşamasında yapmış oldukları katkılarından dolayı editör ve hakemlere teşekkür ederiz.

\section{Kaynaklar}

Adamia, S.A., Lordkipanidze, M.B., ve Zakariadze, G.S. 1977. Evolution of an active continental margin as examplified by the Alpine history of the Caucasus. Tectonophysics, 40, 183-199.

Ağar, Ü., 1977. Demirözü (Bayburt) ve Köse (Kelkit) bölgesinin jeolojisi, Doktora
Tezi, İstanbul Üniversitesi, Fen Fakültesi, İstanbul.

Aliyazicioğlu, İ., 1999. Kale (Gümüshane) yöresi volkanik kayaçlarinin petrografik, jeokimyasal ve petrolojik incelenmesi, Yüksek Lisans Tezi, KTÜ, Fen Bilimleri Enstitüsü, Trabzon.

Alp, D., 1972. Amasya Yöresinin Jeolojisi, İstanbul Üniversitesi Fen Fak. Monografileri, 22, İstanbul, 135.

Altherr, R., Topuz, G., Siebel, W., Şen, C., Meyer, H.P ve Satır, M., 2008. Geochemical and $\mathrm{Sr}-\mathrm{Nd}-\mathrm{Pb}$ isotopic 
characteristics of Paleocene plagioleucitites from the Eastern Pontides (NE Turkey), Lithos, 105, 149-161.

Altunkaynak, L., 2000. A ğvanis masifi doğu kesimi ve çevre kayaçlarının jeolojisi, petrografisi ve jeokimyas1, Doktora Tezi, K.T.Ü., Fen Bilimleri Enstitüsü, Trabzon.

Arslan, M. ve Aliyazıcıŏlu, İ., 2001. Geochemical and Petrological Characteristics of the Kale (Gümüshane) volcanic rocks: Implications for the Eocene evolution of Eastern Pontide arc volcanism, Northeast Turkey, International Geology Review, 43, 595-610.

Arslan, M. ve Aslan, Z., 2006. Mineralogy, petrography and whole-rock geochemistry of the Tertiary granitic intrusions in the Eastern Pontides, NE Turkey, Journal of Asian Earth Sciences, 27, 177-193.

Arslan, M., Şen, C., Aliyazıcıŏglu, İ., Kaygusuz, A. ve Aslan, Z. 2000. Comparative geology, mineralogy and petrology of Eocene (?) volcanics in Trabzon and Gümüşhane areas (NE, Turkey). Earth Science and Mining Conference, Journal of Conference Book 1, 39-53.

Arslan, M., Temizel, İ., Abdioğlu, E., Kolaylı, H., Yücel, C., Boztuğ, D., ve Şen, C., 2013. ${ }^{40} \mathrm{Ar}-{ }^{39} \mathrm{Ar}$ dating, whole-rock and $\mathrm{Sr}-\mathrm{Nd}-\mathrm{Pb}$ isotope geochemistry of post-collisional Eocene volcanic rocks in the southern part of the Eastern Pontides (NE Turkey): implications for magma evolution in extension-induced origin. Contributions to Mineralogy and Petrology, 166, 113-142.

Arslan, M., Tüysüz, N., Korkmaz, S. ve Kurt, H., 1997. Geochemistry and petrogenesis of the eastern Pontide vo1canic rocks, Northeast Turkey, Chemi der Erde, 57, 157-187.

Aslan, Z., 2010. U-Pb zircon SHRIMP age, geochemical and petrographical characateristics of tuffs within calcalkaline Eocene volcanics around Gümüşhane (NE Turkey), Eastern Pontides, Neues Jahrbuch für Mineralogie, 187, 3, 329-346.

Aslan, Z., Arslan, M., Temizel, İ., ve Kaygusuz, A., 2014. K-Ar dating, whole-rock and $\mathrm{Sr}-\mathrm{Nd}$ isotope geochemistry of calc-alkaline volcanic rocks around the Gümüshane area: implications for post-collisional volcanism in the Eastern Pontides, Northeast Turkey. Mineral. Petrol. 108, 245-267.

Aydın, F. 2003. Değirmendere vadisi (Trabzon-Esiroğlu, KD-Türkiye) volkanitlerinin mineral kimyası, petrolojisi ve petrojenezi, Doktora Tezi, K.T.Ü., Fen Bilimleri Enstitüsü, Trabzon.

Aydın, F., Karsli, O. ve Chen, B., 2008. Petrogenesis of the Neogene alkaline volcanics with implcations for post collisional lithospheric thinning of the Eastern Pontides, NE Turkey, Lithos, 104, 249-266.

Aydınçakır, E., 2012. Borçka (Rrtvin, KDTürkiye) Yöresi tersiyer Volkanitlerinin Petrografisi, Jeokimyası ve Petrojenezi, Doktora Tezi, KTÜ, Fen Bilimleri Enstitüsü, 200 Sayfa, Trabzon.

Aydınçakır, E., ve Şen, C., 2013. Petrogenesis of the post-collisional volcanic rocks from the Borçka (Artvin) area: implications for the evolution of the Eocene magmatism in the Eastern Pontides (NE Turkey), Lithos, 172173, 98-117.

Aydınçakırr, E., 2014. The Petrogenesis of Early Eocene Non-adakitic 
Volcanism in NE Turkey: Constraints on the Geodynamic Implications, Lithos, 208/209, 361-377.

Barbieri, M., Conforto, L., Garbarino, C., Masi, U., Nicoletti, M. ve Akıncı, Ö. 2000. Geochemistry of hydrothermally-altered vo1canic rocks of the upper volcanic cycle from the Eastern Pontides (NE Turkey), Chemi der Erde, 60, 81-95.

Baret, T.J. ve MacLean, W.H., 1991. Chemical, mass, and oxygen isotopic changes during extreme hydrothermal alteration of an Archean Rhyolite, Noranda, Economic Geology, 86, 406-441.

Bektaş, O., 1984., Doğu Pontidler'de Üst Kretase Yaşlı Şoşonitik Volkanizma ve Jeotektonik Önemi, K.Ü. Dergisi, 3, 1-2, 53-62, Trabzon.

Boynukalın, S., 1990. Dereli (Giresun) baraj yeri ve göl alanının mühendislik jeolojisi ve çevre kayaçlarının jeomekanik özellikleri, Doktora Tezi, K.T.Ü., Fen Bilimleri Enstittüsü, Trabzon.

Boztuğ, D., Erçin, A.İ., Kuruçelik, M.K., Göç, D., Kömür, İ. ve İskenderoğlu, A., 2006. Geochemical characteristics of the composite Kaçkar batholith generated in a Neo-Tethyan convergence system, Eastem Pontides, Turkey. Journal of Asian Earth Sciences, 27, 286-302.

Boztuğ, D., Jonckheere, R.c., Wagner, G.A. ve Yeğingil, Z., 2004. Slow Senonian and fast Paleocene-Early Eocene uplift of the granitoids in the Central Eastern Pontides, Turkey: apatite fission-track results. Tectonophysics, 382, 213-228.

Bradshaw, T.K. ve Smith, E.I., 1994. Polygenetic Quaternary volcanism at Crater Flat, Nevada, Journal of Volcanology and Geothermal Research, 63, 165-182.
Chen, W. ve Arculus, R.J. 1995. Geochemical and isotopic characteristics of lower crustal xenoliths, San Francisco Volcanic Field, Arizona, U.S.A. Lithos, 110, 99-119.

Churikova, T., Dorendorf, F., ve Wöerner, G., 2001. Sources and fluids in the mantle wedgebelow Kamchatka, evidence from across-arc geochemical variation. Journal of Petrology, 42, 1567-1593.

Condie, K.C., 1993. Chemical composition and evolution of the upper continental crust: contrasting results from surface samples and shales, Chemical Geology, 104, 1-37.

Condie, K.C., Frey, B.A. ve Kerrich, R., 2002. The 1.75-Ga Iron King Volcanics in westcentral Arizona: a remnant of an accreted oceanic plateau derived from a mantle plume with a deep depleted component, Lithos, 64, 49-62.

Çakmak, G., (2013). Pelitli (Bayburt) Granitoyidi'nin Petrografik, Jeokimyasal ve Petrolojik Özelliklerinin İncelenmesi. Yüksek Lisans Tezi, Gümüşhane Üniversitesi, Fen Bilimleri Enstitüsü, Gümüşhane, (Yayınlanmamış), 88s.

Çakmak, G. ve Kaygusuz, A., 2014. Pelitli (Bayburt) Granitoyidi'nin Petrografik ve Jeokimyasal Özellikleri, Gümüşhane Üniversitesi, Fen Bilimleri Enstitüsü Dergisi, 4 (1), 4663.

Çamur, M.Z., Güven, T.B. ve Er, M., 1996. Geochemical characteristics of the eastern Pontide volcanics: An example of multiple volcanic cycles in arc evolution, Turkish Journal of Earth Sciences, 5, 123-144.

Çoğulu, E., 1975. Gümüşhane ve Rize Bölgelerinde Petrografik ve 
Jeokronolojik Araştırmalar, İTÜ Kütüphanesi, 1034, İstanbul.

Dokuz, A. ve Tanyolu, E., 2006. Gechemical constraints on the provenance, mineral sorting and subaerial weathering of lower Jurassic and Upper Cretaceous clastic rocks from the Eastern Pontides, Yusufeli (Arvin), NE Turkey, Turkish Journal of Earth Sciences, 15, 181-209.

Dokuz, A., 2000. Yusufeli yöresinin jeolojisi, jeotektoniği, magmatik-metamorfik kayaçların jeokimyası ve petrojenezi, Doktora Tezi, K.T.Ü., Fen Bilimleri Enstitüsü, Trabzon.

Dokuz, A., 2011. A slab detachment and delamination model for the generation of Carboniferous high-potassium Itype magmatism in the Eastern Pontides, NE Turkey: Köse composite pluton, Godwana Research, 19, 926-944.

Drummond, M. S. ve Defant, M. J., 1990. A model for trondhjemite-tonalite-dacite genesis and crustal growth via slabmelting: Archean to modern comparisons. Journal of Geophysical Research, 95, 21503-21521.

Elburg, M.A, Bergen, M.V., Hoogewerff, J., Foden, J., Vroon, P., Zulkarmain, I. ve Nasution, A., 2002. Geochemical trends across an arc-continent collision zone: magma sources and slab-wedge transfer processes below the Pantar Strait volcanoes, Indonesia, Geochimica et Cosmochimica Acta, 66, 2771-2789.

Erentöz, C., ve Ketin İ. 1974. Explanatory text of the geological map of Turkey at 1/500.000 G scale (Kars). Special Publication of Mineral Research and Exploration, 57.

Eyüboğlu, Y., 2006. Doğu Pontid Magmatik Yayı'nda (KD Türkiye) Alaska-Tip Mafik- Ultramafiklerin Tanımı ve
Jeotektonik Önemi, Doktora Tezi, K.T.Ü., Fen Bilimler Enstitüsü, Trabzon.

Eyüboğlu, Y., 2010. Late Cretaceous high-K volcanism in the Eastern Pontide Orogenic Belt, and its implications for the geodynamic evolution of NE Turkey. International Geology Review, 52 (2-3), 142-186.

Eyüboğlu, Y., Chung, S.L., Santosh, M., Dudas, F.O. ve Akaryali, E., 2011a, Transition from shoshonitic to adakitic magmatism in the Eastern Pontides, NE Turkey: implications for slab window melting, Gondwana Research, 19, 413-429.

Eyüboğlu, Y., Santosh, M., Dudas, F.O., Chung, S.L. ve Akaryal1, E., 2011 b. Migration magmatism in a continental arc: Geodynamics of the Eastern Mediterranean revisited, Journal of Geodynamics, 52, 2-15.

Fitton, J.G., James, D. ve Leeman, W.P. 1991. Basic magmatism associated with Late Cenozoic extension in the western United States: compositional variations in space and time. Journal of Geophysical Research, 96, 1369313712.

Fujimaki, H., Tatsumoto, M. ve Aoki, K., 1984. Partition coefficients of $\mathrm{Hf}, \mathrm{Zr}$ and REE between phenocrysts and groundmasses, Proc. 4th Lunar Planet Sci Conf. 2. Journal of Geophysical Research, 89, B662-672.

Gedik, A., Ercan, T., Korkmaz, S. ve Karataş, S., 1992. Rize-Fındıklı Çamlıhemşin arasında (Doğu Karadeniz) yer alan magmatik kayaçların petrolojisi ve Doğu Pontidlerdeki bölgesel yayılımları, Türkiye Jeoloji Bülteni, $35,15-38$.

Gill, J.B., 1981. Orogenic andesites and plate tectonics, Springer, Berlin, 390p. 
Güngör, Y., Boztuğ, D. ve Y1lmaz, O., 1997. Kaçkar Batoliti Altıparmak DağıSoğanlı Dağı arası (GD ÇamlıhemşinRize) kesiminin petrografik, jeokimyasal ve petrojenetik incelenmesi. Çukurova Üniversitesinde Jeoloji Mühendisliği Eğitiminin 20. Y1lı Sempozyumu, 30 Nisan - 3 Mayıs 1997, Adana, Bildiri Özetleri, s. 223-224.

Güven İ.H. 1993. Doğu Karadeniz Bölgesi'nin 1/25.000 ölçekli jeolojisi ve komplikasyonu, MTA, Ankara (yayınlanmamış).

Hawkesworth, C.J.,Turner, S., McDermott, F., Peate, D. ve Van Calsteren, P., 1997. U-Th isotopes in arc magmas: implications for element transfer from the subducted crust, Science, 276, 551-555.

Hofmann, A.W., 1988. Chemical differentiation of the Earth: the relationship between mantle, continental crust and oceanic crust, Earth and Planetary Science Letters, 90, 297-314.

Hofmann, A.W., 1997. Mantle geochemistry: the message from oceanic volcanism, Nature, 385, 219-229.

Irvine, T. N. ve Baragar, W.R.A., 1971. A guide to the chemical classification of common volcanic rocks, Canadian Journal of Earth Sciences, 8, 523-548.

Jahn, B.M. ve Zhang, Z.Q., 1984. Archean granulite gneisses from eastern Hebei Province, China: rare earth geochemistry and tectonic implications, Contributions to Mineralogy and Petrology, 85, 224243.

Jahn, B.M., Wu, F.Y. ve Lo, C.H., 1999. Crust-mantle interaction induced by deep subduction of the continental crust: geochemical and $\mathrm{Sr}-\mathrm{Nd}$ isotopic evidence from post-collisional mafic- ultramafic intrusions of the northern Dabie Complex, Central China, Chemical Geology, 157, 119-146.

Jica, 1986. The republic of Turkey report on the cooperative mineral exploration of Gümüşhane area, consolidated report. Japan International Cooperation Agency, 146 pp.

Karslı, O., Aydın, F. ve Sadıklar, B., 2004. The morphology and chemistry of Kfeldsper megacrysts from İkizdere Pluton: evidence for acid and basic magma interactions in granitoid rocks, NE Turkey, Chemie der ErdeGeochemistry, 64, 155-170.

Karslı, O., Chen, B., Aydın, F. ve Şen, C., 2007. Geochemical and $\mathrm{Sr}-\mathrm{Nd}-\mathrm{Pb}$ isotopic compositions of the Eocene Dölek and Sarıçiçek Plutons, Eastern Turkey: implications for magma interaction in the genesis of high-K calc-alkaline granifoids in a postcollision extensional serting, Lithos, 98, 67-96.

Karslı, O., Dokuz, A., Uysal, İ., Aydın, F., Kandemir, R. ve Wijbrans, J.R., 2010. Generation of the Early Cenozoic adakitic volcanism by partial melting of mafic lower crust, Eastern Turkey: implication for crustal thickening to delamination, Lithos, 114, 109-120.

Karslı, O., Uysal, İ., Ketenci, M., Dokuz, A., Aydin, F., Chen, B., Kandemir, R. ve Wijbrans, J., 2011. Adakite-like granitoid porphyries in Eastern Pontides, NE Turkey: potential parental melts and geodynamic implications, Lithos, 127, 354-372.

Kaygusuz A. ve Aydınçakır, E., 2011b. U-Pb zircon SHRIMP ages, geochemical and $\mathrm{Sr}-\mathrm{Nd}$ isotopic compositions of Cretaceous Plutons in the Eastern Pontides (NE Turkey): the Dağbaşı Pluton. Neues Jahrbuch Für Mineralogie, 188/, 211-233. 
Kaygusuz, A., Arslan, M., Sipahi, F., ve Temizel, İ. 2016. U-Pb zircon Chronology and Petrogenesis of Carboniferous plutons in the northern part of the Eastern Pontides, NE Turkey: constraints for Paleozoic magmatism and geodynamic evolution. Gondwana Research, doi:10.1016/j.gr.2016.01.011.

Kaygusuz, A. ve Aydınçakır, E., 2009. Mineralogy, Whole-Rock and $\mathrm{Sr}-\mathrm{Nd}$ isotope geochemistry of mafic microgranular enclaves in Cretaceous Dağbaşı Granitoids, Eastern Pontides, NE Turkey: Evidence of magma mixing, mingling and chemical equilibration. Chemie der Erde, 69, 247-277.

Kaygusuz, A. ve Şen, C., 2011. Calc-alkaline I-Type plutons in the Eastern Pontides, NE Turkey: U-Pb zircon ages, geochemical and $\mathrm{Sr}-\mathrm{Nd}$ isotopic compositions. Chemie der Erde, 71, 59-75.

Kaygusuz, A., Sipahi, F., İlbeyli, N., Arslan. M., Chen, B., ve Aydınçakır, E., 2013. Petrogenesis of the Late Cretaceous Turnagöl intrusion in the Eastern Pontides: Implications for magma genesis in the arc setting. Geoscience Frontiers, 4; 423-438.

Kaygusuz, A., 2000. Torul ve Çevresinde Yüzeylenen Kayaçların Petrografik ve Jeokimyasal İncelenmesi, Doktora Tezi, KTÜ, Fen. Bil. Enst., 235 Sayfa, Trabzon.

Kaygusuz, A., 2009. K/Ar ages and geochemistry of the collision related volcanic rocks in the Ilica (Erzurum) area, eastern Turkey, Neues Jahrbuch für Mineralogie, 186, 21-36.

Kaygusuz, A., Arslan, M., İlbeyli, N., Sipahi, F. ve Aydınçakır, E., 2012b. Doğu Pontid Kuzey Zonunda yüzeylenen Paleozoyik yaşlı granitlerin U-Pb zirkon yaşlandırması, $\mathrm{Sr}-\mathrm{Nd}-\mathrm{Pb}-\mathrm{O}$ izotop sistematikleri ve jeodinamik evrimi, (TÜBITTAK PROJESI) Proje No: 109Y052.

Kaygusuz, A., Arslan, M., Siebel, W. ve Şen, C., 2011a. Geochemical and $\mathrm{Sr}-\mathrm{Nd}$ Isotopic Characteristics of PostCollisional Calc-Alkaline Volcanics in the Eastern Pontides (NE Turkey). Turkish Journal of Earth Sciences, 20, 137-159.

Kaygusuz, A., Arslan, M., Wolfgang, S., Sipahi, F. ve İlbeyli, N., 2012a. Geochronological evidence and tectonic significance of Carboniferous magmatism in the southwest Trabzon area, Eastern Pontides, Turkey. International Geology Rew, 54 (15), 1776-1800.

Kaygusuz, A., Arslan, M., Wolfgang, S., Sipahi, F., İlbeyli, N., ve Temizel, İ. 2014. LA-ICP MS zircon dating, whole-rock and $\mathrm{Sr}-\mathrm{Nd}-\mathrm{Pb}-\mathrm{O}$ isotope geochemistry of the Camiboğazı pluton, Eastern Pontides, NE Turkey: implications for lithospheric mantle and lower crustal sources in arcrelated I-type magmatism, Lithos, 192-195, 271-290.

Kaygusuz, A., Chen, B., Aslan, Z., Siebel, W. ve Şen, C., 2009. U-Pb zircon SHRIMP ages, geochemical and sr-nd 1sotopic compositions of the Early Cretaceous I-Type Sariosman Pluton, Eastern Pontides, NE Turkey. Turkish Journal of Earth Sciences, 18, 549-581.

Kaygusuz, A., ve Öztürk, M., 2015. Geochronology, geochemistry, and petrogenesis of the Eocene Bayburt intrusions, Eastern Pontide, NE Turkey: implications for lithospheric mantle and lower crustal sources in the high-K calc-alkaline magmatism. Journal of Asian Earth Sciences, 108, 97-116. 
Kaygusuz, A., Siebel, W., İlbeyli, N., Arslan, M., Satır, M. ve Şen, C., 2010. Insight Into Magma Genesis at Convergent Plate Margins - A Case Study From the Eastern Pontides (NE Turkey). Neues Jahrbuch für Mineralogie, 187/3, 265-287.

Kaygusuz, A., Siebel, W., Şen, C. ve Satır, M., 2008. Petrochemistry and petrology of I-type granitoids in an arc setting: The composite Torul Pluton, Eastern Pontides, NE Turkey. International Journal of Earth Sciences, 97, 739-764.

Kazmin, V.G., Sbortshıkov, I.M., Ricou, L.E., Zonenshain, L.P.,Boulin, J. ve Knipper, A.L. 1986. Volcanic belts as marker ofthe Mesozoic-Cenozoic evolution of Tethys. Tectonophysics, $123,123-152$.

Ketin, İ., 1983. Türkiye jeolojisine genel bir bakış, İ.T.Ü. Kütüphanesi, 1259, 536.

Kırmac1, Z. 1992. Alucra-GümüşhaneBayburt Yörelerindeki (Doğu Pontid Güney Zonu) Üst Jura-Alt Kretase Yaşlı Berdiga Kireçtaşı'nın Sedimantolojik İncelemesi, Doktora Tezi, K.T.Ü. Fen Bilimleri Enstitüsü, Trabzon.

Korkmaz, S., Tuysuz, N., Er, M., Musaoğlu, A. ve Keskin, İ., 1995. Stratigraphy of the eastern Pontides, NE Turkey.

Köprübaşı, N., Şen, C. ve Kaygusuz, A., 2000. Doğu Pontid ada yay1 granitoyidlerin karşılaştırılmalı petrografik ve kimyasal özellikleri, Uygulamalı Yerbilimleri, 1, 111-120.

Lambert, R.J. ve Holland, JG., 1974. Yttrium geochemistry applied to petrogenesis utilizing calcium-yttrium relationships in minerals and rocks, Geochimica et Cosmochimica Acta, 38, 1393-1414.
Le Maitre, R.W., Bateman, P., Dudek, A., Keller, J., Lameyre Le Bas, M.J., Sabine, P.A., Schmid, R., Sorensen, H., Streckeisen, A., Woolley, A.R. ve Zanettin, B., 1989. A classification of 1gneous rocks and glossary of terms, Blackwell, Oxford.

McDermott, F., Delfin, F.G., Defant, M.J., Turner, S. ve Maury, R., 2005. The petrogenesis of magmas from Mt. Bulusan and Mayon in the Bicol arc, the Philippines, Contributions to Mineralogy and Petrology, 150, 652670.

Okay, A.I. ve Şahintürk, Ö., 1997. Geology of the Eastern Pontides, In: Robinson, A.G. (Editor), Regional and petroleum geology of the Black Sea and surrounding region, American Association Petroleum Geologists, 68, 291-311.

Okay, A.I., 1984. Distribution and characteristics of the northwest Turkish blueschists. In: The Geological Evolution of the Eastern Mediterranean (ed. J.E. Dixon ve A.H.F. Robertson), Geological Society Special Publication, 17, 455466.

Okay, A.I., Şahintürk, Ö. ve Yakar, H., 1997. Stratigraphy and tectonics of the Pulur (Bayburt) region in the Eastern Pontides, Mineral Research Exploration Bulletin, 119, 1-24.

Özcan, A., Erkan, A., Keskin, A., Keskin, E., Oral, A., Özer, S., Sümegen, M. ve Tekeli, O., 1980. Amasya-Turhal arasındaki bölgenin jeolojisi, MTA Rap. No: 6722.

Özdoğan, K., 1992. Karadağ (TorulGümüşhane) ve yakın çevresinin jeolojisi-mineralojisi-petrografisi ve maden zuhurlarının jenetik incelenmesi, Doktora Tezi, Selçuk Üniv. Fen Bil. Enstitüsü, Konya. 
Özsayar, T., Pelin, S., ve Gedikoğlu, A., 1981. Doğu Pontidler'de Kretase, KTÜ Yer Bilimleri Dergisi, cilt 1, 65114.

Öztürk, 2014., K1lıçkaya (Bayburt) Granitoyidinin petrografik, jeokimyasal ve petrolojik özelliklerinin incelenmesi, Yüksek Lisans Tezi, Gümüşhane Üniversitesi, Fen Bilimleri Enstitüsü, Jeoloji Mühendisliği Bölümü, 100s.

Pearce, J.A. ve Cann, J.R., 1973. Tectonic setting of basic volcanic rocks determined using trace element analyses, Earth and Planetary Science Letters, 19, 290-300.

Pearce, J.A. ve Peate, D.W., 1995. Tectonic implications of composition of volcanic arc magmas, Annual Review of Earth and Planetary Sciences, 23, 251-285.

Pearce, J.A., 1983. Role of the subcontinental lithosphere in magma genesis at active continental margins. In C. J., Hawkesworth ve M. J. Norry, (eds.), Continental basalts and mantle xenoliths, Shiva, Cheshire, 230-249.

Pearce, J.A., Bender, J.F., De Long, S.E., Kidd, W.S.F., Low, PJ., Güner, Y., Şaroğlu, F., Y1lmaz, Y., Moorbath, S. ve Mitchell, J.J., 1990. Genesis of collision volcanism in eastern Anatolia Turkey, Journal of Volcanology and Geothermal Research, 44, 189-229.

Pelin, S. 1977. Alucra (Giresun) Güneydogu yöresinin petrol olanakları bakımından jeolojik incelenmesi, K.TÜ. Yayınları, 87, 103s, Trabzon.

Perfit, M.R., Gust, D.A., Bence, A.R., Arculus, R.J. ve Taylor, S.R., 1980. Chemical characteristic of 1sland-arc basalts: Implications for mantle sources, Chemical Geology, 30, 227256.
Rickwood, P.C., 1989. Boundary lines within petrologic diagrams, which use oxides of major and minor elements. Lithos. 22, 247-263.

Rogers, N., Macdonald, R., Fitton, J. G., George, R., Smith, M. ve Barreiro, B. 2000. Two Mantle Plumes Beneath the East African Rift System: Sr, Nd and $\mathrm{Pb}$ Isotope Evidence from Kenya Rift Basalts. Earth and Planetary Science Letters, 176, 387-400.

Rojay, B., 1993. Tectonostratigraphy and neotectonic characteristics of the southern margin of Merzifon-Suluova Basin (Central Pontides, Amasya), Phd Thesis, Middle East Technical University, Ankara.

Saydam Eker, C., Sipahi, F. ve Kaygusuz A., 2012. Trace and Rare Earth Elements as Indicators of Provenance and Depositional Environments of Lias Cherts in Gumushane, NE, Turkey, Chemie der Erde, 72, 167-177 pp.

Schmidberger, S.S. ve Hegner, E., 1999. Geochemistry and isotope systematics of calcalkaline volcanic rocks from the Saar-Nahe basin (SW German)implications for Late Variscan orogenic development, Contributions to Mineralogy and Petrology, 135, 373-385.

Schultze-Westrum, H.H. 1961. Giresun civarındaki Aksu Deresinin jeolojik profili, Kuzeydoğu Anadolu'da Doğu Pontus cevher ve mineral bölgesinin jeolojisi ve maden yatakları ile ilgili mütealalar, MTA Dergisi, 57, 63-71.

Sipahi, F., 2005. Zigana Dağ1 (TorulGümüşhane) volkanitlerindeki hidrotermal ayrıșmaların mineraloji ve jeokimyas1, KTÜ Fen Bilimleri Enstitüsü, Doktora Tezi, Trabzon.

Sipahi, F., Sadıklar, M. B., ve Șen, C., 2014. Geochemical and $\mathrm{Sr}-\mathrm{Nd}$ Isotopic 
Characteristics of Murgul (Artvin) Volcanics in the Eastern Black Sea Region (NE Turkey). Chemie der Erde-Geochemistry, 74, 331-342.

Sipahi, F., ve Sadıklar, M. B.,. 2014. Geochemistry of Dacitic Volcanics in the Eastern Pontide (NE Turkey). Geochemistry International, 52, 4, 329-349.

Sipahi, F.,2011. Formation of Skarns at Gümüşhane (Northeastern Turkey). Neues Jahrbuch für MineralogyAbhandlungen, 188, 2, 169-190.

Smith, E.I., Sanchez, A., Walker, J.D. ve Wang, K., 1999. Geochemistry of mafic magmas in the Hurricane Volcanic fieid, Utah: implications for small and large scale chemical variability of yhe lishosheric mantle, Journal of Geology, 107, 433-448.

Sun, S. ve McDonough, W.F., 1989. Chemical and isotopic systematics of oceanic basalt: Implications for mantle composition and processes, In: A. D. Saunders, ve M.J. Norry, (eds.), Magmatism in the Ocean Basins, Geological Societv of London Special Publication, 42, 313-345.

Şahin, K., 2014. Mescitli (Gümüşhane) ve çevresindeki Eosen yaşlı volkanik kayaçların petrografik, jeokimyasal ve petrolojik özeliklerinin incelenmesi, Yüksek Lisans Tezi, G.Ü. Fen Bilimleri Enstitüsü, 96 sayfa.

Şahin, S. Y., Güngör, Y. ve Boztuğ, D., 2004. Comparative petrogenetic investigation of Composite Kaçar Batholith granitoids in Eastern Pontide magmatic arc, Northern Turkey. Earth Planets Space, 56, 429446.

Şen, C. 2000. Doğu Pontid alkalen provensine (KD, Türkiye) ait Eosen sonras1 kayaçlar içerisinde bulunan ultramafik nodüllerin petrografisi, mineralojisi ve kimyası, Cumhuriyetin 75. Yildönümü Yerbilimleri ve Madencilik Kongresi, Mayıs, Ankara, Bildiri Özleri Kitabı, 1, 55-66.

Şen, C., 2007. Jurassic volcanism in the Eastern Pontides: Is it rift related or subduction related?, Turkish Journal of Earth Sciences, 16, 523-539.

Şen, C., Arslan, M. ve Van. A. 1998. Doğu Pontid (Kd Türkiye) Eosen (?) alkalen volkanik provensinin jeokimyasal ve petrolojik karakteristikleri, Tübitak Yayinlari, Turkish Journal of Earth Sciences, 7, 231-239.

Şengör, A.M.C. ve Y1lmaz, Y., 1981. Tethyan evolution of Turkey: a plate tectonic approach. Tectonophysics, 75, 181241.

Taslı, K., 1984. Hamsiköy (Trabzon) yöresinin jeolojisi, K.Ü., Dergisi, 3, 69-76.

Tasl1, K., 1990. Gümüşhane-Bayburt yörelerindeki Üst Jura-Alt Kretase yaşlı karbonat istiflerinin stratigrafisi ve mikropaleontolojik incelemesi, Doktora Tezi, K.T.Ü., Fen Bilimleri Ensitüsü, Trabzon.

Taylor, S.R. ve McLennan, S.M., 1985. The continental crust, its composition and evolution. Blackwell, Oxford, 312.

Temizel, İ. ve Arslan, M., 2008. Petrology and geochemistry of Tertiary volcanic rocks from the İkizce (Ordu) area, NE Turkey: implications for the evolution of the eastern Pontide paleomagmatic arc, Journal of Asian Earth Sciences, 31, 4-6, 439-463.

Temizel, İ. ve Arslan, M., 2009. Mineral chemistry and petrochemistry of postcollisional Tertiary mafic to felsic cogenetic volcanics in the Ulubey 
(Ordu) area, Eastern Pontides, NE Turkey, Turkish Journal of Earth Sciences, 18, 29-53.

Temizel, İ., 2008. Ulubey (Ordu-KD Türkiye) yöresi Tersiyer volkanitlerinin petrografisi, petrokimyas $1,{ }^{40} \mathrm{Ar}-{ }^{39} \mathrm{Ar}$ jeokronoloji, Sr-Nd izotop jeokimyası ve petrojenezi, Doktora Tezi, K.T.Ü., Fen Bilimleri Enstitüsü, Trabzon.

Temizel, İ., Arslan, M., Ruffet, G. ve Peucat, J.J., 2012. Petrochemistry, geochronology and $\mathrm{Sr}-\mathrm{Nd}$ isotopic systematic of the Tertiary collisional and post-collisional volcanic rocks from the Ulubey (Ordu) area, eastern Pontide, NE Turkey: implications for extension-related origin and mantle source characteristics, Lithos, 128, 126-147.

Tokel, S., 1972. Stratigraphical and volcanic history of the Gümüşhane region (Ne Turkey), Ph. D. Thesis, University Colloge, London.

Tokel, S., 1977. Doğu Karadeniz bölgesi'nde Eosen yaşlı kalk-alkalen andezitler ve jeotektonizma, TJK Bülteni, 20,1, 49-54.

Topuz, G. ve Altherr, R., 2004. Pervasive rehydration of granulites during exhumation-an example from the Pulur complex, Eastern Pontides, Turkey, Mineralogy and Petrology, 81, 165-185.

Topuz, G., Altherr, R., Kalt, A., Satır, M., Wemer, O. ve Schwarz, W.H., 2004a. Aluminous granulites from the Pulur complex, NE Turkey: a case of partial melting, efficient melt extraction and crystallization, Lithos, 72, 183-207.

Topuz, G., Altherr, R., Satır, M. ve Schwarz, W.H., 2004b. Low-grade metamorphic rocks from the Pulur complex, NE Turkey: implications for pre-Liassic evolution of the Eastern Pontides, International Journal of
Earth Science (Geol Rundsch), 93, 72-91.

Topuz, G., Altherr, R., Schwarz, W.H., Dokuz, A. ve Meyer, H.P., 2007. Variscan amphibolite-facies rocks from the Kurtoğlu metamorphic complex. Gümüşhane area, Eastern Pontides, Turkey, International Journal of Earth Sciences, 96, 861873.

Topuz, G., Altherr, R., Schwarz, W.H., Siebel, W., Satir, M. ve Dokuz, A., 2005. Post-collisional plutonism with adakite-like signatures: the Eocene Saraycik granodiorite (Eastern Pontides, Turkey), Contributions to Mineralogy and Petrology, 150, 441455.

Topuz, G., Altherr, R., Wolfgang, S., Schwarz, W.H., Zack, T., Hasanözbek, A., Mathias, B,. Satır, M. ve Şen, C., 2010. Carboniferous high-potassium I-type granitoid magmatism in the Eastern Pontides: The Gümüşhane pluton (NE Turkey), Lithos, 116, 92-110.

Topuz, G., Okay, A.I., Altherr, R., Schwarz, W.H., Siebel, W., Zack, T., Satir, M. ve Şen, C., 2011. Post-collisional adakite-like magmatism in the Ağvanis massif and implications for the evolution of the Eocene magmatism in the Eastern Pontides (NE Turkey), Lithos, 125, 131-150.

Turner, S.P., 2005. Some remarks on magmatic processes beneath island arc volcanoes. Adevances in Science, Earth Sciences, Imperial College Press, 131-155.

Tüysüz, O., 1996. Amasya ve çevresinin jeolojisi, Türkiye 11. Petrol Kongresi Bildirileri, 32-48.

Ustaömer, T. ve Robertson, H.F.A, 2010. Late Paleozoic-Early Cenozoic development of the Eastern Pontides 
(Artvin area), Turkey: stages of closure of Tethys along the southern margin of Eurasia, Spacial Publications, Geological Society London, 340, 281-327.

Weaver, B.L., Wood, D.A., Tarney, J. ve Joron, J., 1987. Geochemistry of ocean island basalt from the South Atlantic: Ascension, Bouvet, St. Helena, Gough and Tristan da Cunda. In: Fitton, J.G ve Upton, B.G.J. (eds), Alkaline igneous rocks, Geological Society, London, Special Publications, 30, 253-267.

Winchester, J.A. ve Floyd, P.A. 1977. Geochemical discrimination of different magma series and their differentiation products using immobile elements. Chemical Geology, 20, 325-343.

Y1lmaz, A., Engin, T., Adamia S. ve Lazarashvili T. 1997. Geoscientific studies of the area along TurkishGeorgian Border, MTA, Ankara.

Y1lmaz, C., 2002. Gümüşhane-Bayburt yöresindeki mesozoyik havzalarının tektono-sedimantolojik kayıtları ve kontrol etkenleri, Türkiye Jeoloji Bülteni, 45, 1, 141-165.

Y1lmaz, S. ve Boztuğ, D., 1996. Space and time relations of three plutonic phases in the Eastern Pontides, Turkey, International Geology Review, 38, 935-956.

Y1lmaz, Y., 1976. Geochemical study of the Gümüşhane Granite, İst. Üniv. Fen. Fak. Mec. Seri B, 39, 3-4, 173-203.

Yılmaz, Y., Tuysuz, O., Yiğitbaş, E., Genc, Ş.C. ve Şengor, A.M.C., 1997. Geology and tectonics of the Pontides. In: ROBINSON, A.G. (ed), Regional and Petroleum Geology of the Black Sea and Surrounding Region. American Association of
Petroleum Geologists (AAPG)

Memoir 68, 183-226.

Yücel, C., 2013. Trabzon-Giresun arasındaki Tersiyer volkanitlerinin petrografisi, ${ }^{40} \mathrm{Ar}-{ }^{39} \mathrm{Ar}$ jeokronolojisi, petrokimyas1, $\quad \mathrm{Sr}-\mathrm{Nd}-\mathrm{Pb}$ izotop jeokimyası ve petrolojisi, Doktora Tezi, K.T.Ü. Fen Bilimleri Enstitüsü, 285 sayfa.

Yücel, C., Arslan, M., Temizel, İ., ve Abdioğlu, E., 2014. Volcanic facies and mineral chemistry of Tertiary volcanics in the northern part of the Eastern Pontides, northeast Turkey: Implications for pre-eruptive crystallization conditions and magma chamber processes, Mineralogy and Petrology, 108, 439-467.

Zankl, H. 1962. Magmatismus und Bauplan des Ostrpontishen Gebirges im Querprofil des Harşit-Tales, Bayerische Akademie der Wissenschaften. Abhandlungen. Neue Folge, Heft 109, 61-90, Münhen.

Zellmer, G.F., Annen, C., Charlier, B.L.A., George, R.M.M., Turner, S.P. ve Hawkesworth, C.J. 2005. Magma evolution and ascent at volcanic arcs: constraining petrogenetic processes through rates and chronologies. Journal of Volcanology and Geothermal Research, 140, 171-191.

Zhao, D., Lei, J., Inoue, T., Yamada, A., Gao, ve S., 2006. Deep structure and origin of the Baikal rift zone. Earth and Planetary Science Letters, 243, 681691. 